\title{
Towards Enhanced Catalytic Activity of Magnetic Nanoparticles Integrated into 3D Reduced Graphene Oxide for Heterogeneous Fenton Organic Dye Degradation
}

\section{Fatemeh Sadegh}

University of Sistan and Baluchestan

Nikolaos Politakos

POLYMAT, University of the Basque Country UPV/EHU

Oihane Sanz

University of the Basque Country, UPV/EHU

Ali Reza Modarresi-Alam

University of Sistan and Baluchestan

Radmila Tomovska ( $\square$ radmila.tomovska@ehu.es)

POLYMAT, University of the Basque Country UPV/EHU

\section{Research Article}

Keywords: 3D graphene aerogels, Fe304, Heterogeneous Fenton reaction, Acid Green 25, Reduced graphene oxide

Posted Date: April 21st, 2021

DOI: https://doi.org/10.21203/rs.3.rs-442264/v1

License: (c) (i) This work is licensed under a Creative Commons Attribution 4.0 International License.

Read Full License 


\title{
Towards enhanced catalytic activity of magnetic nanoparticles integrated into 3D
} reduced graphene oxide for heterogeneous Fenton organic dye degradation

\author{
Fatemeh Sadegh, ${ }^{a, b}$ Nikolaos Politakos, ${ }^{a}$ Oihane Sanz, ${ }^{c}$ Ali Reza Modarresi-Alam,,${ }^{b, d}$
} and Radmila Tomovska, ${ }^{a, \text {,* }}$

\author{
${ }^{\text {a }}$ POLYMAT, Facultad de Ciencias, Químicas, University of the Basque Country UPV/EHU, Joxe Mari Korta, \\ Center - Avda. Tolosa, 72, San Sebastian, 20018, Spain. E-mail: radmila.tomovska@ehu.es \\ ${ }^{\mathrm{b}}$ Organic and Polymer Research Laboratory, Department of Chemistry, Faculty of Science, University of Sistan \\ and Baluchestan, Zahedan, Iran. \\ ${ }^{\mathrm{c}}$ Departamento de Química Aplicada, Facultad de Ciencias, Químicas, University of the Basque Country, \\ UPV/EHU, P. Manuel de Lardizabal 3, San Sebastian, 20018, Spain. \\ ${ }^{\mathrm{d}}$ Renewable Energies Research Institute, University of Sistan and Baluchestan, Zahedan, Iran. \\ ${ }^{\mathrm{e}}$ Ikerbasque, Basque Foundation for Science, Maria Diaz de Haro 3, Bilbao, 48013, Spain.
}

\begin{abstract}
Composite Fenton nanocatalyst was prepared by water-based in situ creation of $\mathrm{Fe}_{3} \mathrm{O}_{4}$ nanoparticles integrated within self-assembly $3 \mathrm{D}$ reduced graphene oxide (rGO) aerogel. It was used for degradation of Acid Green 25 (AG-25) organic dye in aqueous solution, in presence of $\mathrm{H}_{2} \mathrm{O}_{2}$. By investigating the conditions that maximize the dye adsorption by the 3D composite, it was found that the $\mathrm{pH}$ of the solution should be adjusted between the $\mathrm{pKa}$ of the functional groups presented on the rGO surface (carboxylic acid) and that of the dye (sulfonic acid) to promote electrostatic interactions dye - 3D structure. Performed under these conditions, Fenton degradation of AG-25 in presence of $\mathrm{H}_{2} \mathrm{O}_{2}$ was completed in less than 30 min, including all the intermediate products, as demonstrated by MALDI-TOF-MS analysis of the aqueous solution after discoloration. Moreover, this was achieved in a solution with as high dye concentration
\end{abstract}


as $0.5 \mathrm{mg} / \mathrm{mL}$, with only $10 \mathrm{mg}$ of $3 \mathrm{D}$ composite catalyst, at room temperature and without additional energy input. The high performance was attributed to the creation of charge transfer complex between the rGO and $\mathrm{Fe}_{3} \mathrm{O}_{4}$ nanoparticles throughout covalent bond $\mathrm{C}-\mathrm{O}-\mathrm{Fe}$, the formation of which was promoted by the in situ synthesis procedure.

Keywords: 3D graphene aerogels, $\mathrm{Fe}_{3} \mathrm{O}_{4}$, Heterogeneous Fenton reaction, Acid Green 25, Reduced graphene oxide

\section{Introduction}

Organic dyes are complex and toxic aromatic compounds, usually used to dye textiles or other products. ${ }^{1}$ However, the effluents produced during dyeing processes are characterized with intense color and toxicity and have strong impact for the environment. Therefore, purification of these effluents in order to reuse the residual water or to release it in atmospheric waters is of huge importance, urged additionally by the universal lack of fresh water. One of the most investigating dye removal technique is adsorption with solid adsorbentsy, ${ }^{2-4}$ because the technique is low cost and simple. ${ }^{5,6}$ Suitable solid adsorbents investigated for that aim are: activated carbon, zeolite, clay, some metals, raw coal, wood chips, silica, metal oxides and resin polymers. ${ }^{6-9}$ The performance of these adsorbents was improved by decreasing their size to nano-level, due to the increase in the active specific surface area. ${ }^{10-12}$ Recently, graphene has aroused as a good candidate for organic dye adsorption, due to the excellent and unique properties, such as high surface area, flexibility and chemical, mechanical and thermal stability. ${ }^{13-16}$ It was already demonstrated that graphene is an excellent adsorbent for various organic compounds, including organic dyes. ${ }^{17-21}$ Moreover, the graphene based 3D aerogel nanostructures has shown to be even more efficient adsorbents ${ }^{22-25}$ that already have practical application for water purification. However, adsorption of pollutants resolves only half of the 
problem, because the adsorbed dyes should be further either disposed or eliminated. ${ }^{26-28}$ Simultaneous catalytic elimination of organic dyes from polluted water by high performance adsorbent, such as 3D rGO structures with anchored catalysts on the surface became a promising for organic wastewaters treatment. ${ }^{29}$ Between various catalytic processes studied, Fenton reaction over magnetic nanoparticles as catalysts combined with the 3D rGO aerogel structures have arisen as potential advanced oxidation technique for organic dye elimination. ${ }^{30-}$ 34

Recently, we have proposed a green synthesis method for efficient combination of 3D reduced graphene oxide (rGO) aerogel structure with magnetic iron nanoparticles, using aqueous media and mild synthesis conditions. ${ }^{35}$ The process was evaluated using acid red organic azo dye, which was eliminated from the aqueous solution by Fenton oxidation process in presence of $\mathrm{H}_{2} \mathrm{O}_{2}$. The dye and the primary degradation products containing conjugated aromatic rings were completely degraded, however, some of the lower molar mass aromatic degradation products persisted after the treatment. The resulting nanocomposite catalyst have shown to be a solid base for an efficient treatment technology development. Even though optimization of the Fenton process was performed based on the quantity of the solid adsorbent and the concentration of $\mathrm{H}_{2} \mathrm{O}_{2}$, further optimization is necessary in order to achieve complete mineralization of the adsorbed dye and all degradation products, which is a subject of the present work.

The main advantages of the Fenton process are the ambient working temperature and pressure, resulting in lower energy consumption even than UV/Vis light based reactions (photocatalysis), moreover it may be efficiently applied at very low concentrations of the organic pollutants. ${ }^{36}$ The mechanism of Fenton oxidation of organic pollutant (RHX) degradation occurs according to Equation (1-3): $:^{37}$ 
$\mathrm{H}_{2} \mathrm{O}_{2}+\mathrm{Fe}^{2+} \longrightarrow \mathrm{Fe}^{3+}+{ }^{\cdot} \mathrm{OH}+{ }^{-} \mathrm{OH}$

$\mathrm{Fe}^{3+}+\mathrm{H}_{2} \mathrm{O}_{2} \longrightarrow \mathrm{Fe}^{2+}+\mathrm{H}^{+}+{ }^{\cdot} \mathrm{OOH}$

$\mathrm{RHX}+{ }^{\circ} \mathrm{OH} \longrightarrow \mathrm{X}^{-}+$oxidation products (incl. $\mathrm{CO}_{2}+\mathrm{H}_{2} \mathrm{O}$ )

The oxidizing power of the Fenton system degradation mechanism is based on creation ${ }^{\circ} \mathrm{OH}$ radicals by decomposition of $\mathrm{H}_{2} \mathrm{O}_{2}$ onto iron ion $\left(\mathrm{Fe}^{2+}\right)$ promoter. ${ }^{37}$ It was demonstrated previously that $\mathrm{pH}$ affects the iron ion oxidation, and subsequently it affects the rate of hydroxyl radicals generation. ${ }^{38}$ The optimal range of $\mathrm{pH}$ has been reported to be $2-4 .{ }^{39-42}$ Increasing additionally the $\mathrm{pH}$ usually causes precipitation of iron in a hydroxide form. Nevertheless, $\mathrm{pH}$ of the solution may affect further the quality, the rate and the extent of the interactions between the catalyst and the dye.

Considering that the heterogeneous catalysis consists of few elementary steps, pollutant adsorption, degradation reaction and products desorption, it is clear that degradation efficiency might be affected by the rate of each of these steps. So far, up to the authors' best knowledge, the reported studies focused solely on the heterogeneous Fenton reaction degradation of various organic dyes. ${ }^{38-43}$ However, if the adsorption process of the pollutant is not efficient and slow, it will negatively affect the degradation process. With other words, if the conditions are optimized for selective and fast pollutant adsorption, the efficiency of the overall process might be enhanced.

For that aim, the magnetic nanoparticles Fenton catalyst were integrated into 3D rGO aerogel under mild condition by simultaneous reduction reaction that induced self-assembly creation of porous monolithic structures. Acid green azo organic dye (AG-25) was used as a model dye to study the efficiency of the proposed process. The AG-25 contains conjugated aromatic rings (Fig. 1), which is more complex than the studied acid red dye in our previous work. ${ }^{35}$ 
In this work, by carefully studying solely the process of dye adsorption at different $\mathrm{pHs}$, the optimal $\mathrm{pH}$ to maximize the interaction and subsequently the adsorption was determined, which promoted further the degradation of the dye in presence of peroxide. It is worth mentioning that the process was performed under atmospheric conditions, without use of additional source of energy and have presented $100 \%$ efficiency, with respect to the AG-25 and all the aromatic secondary degradation products, as demonstrated by MALDI-TOF-MS technique.

\section{Experimental}

\section{Materials}

Ferrous sulfate $\left(\mathrm{FeSO}_{4} \cdot 7 \mathrm{H}_{2} \mathrm{O}\right)$, poly(vinyl pyrrolidone) (PVP; 10,000 $\left.\mathrm{g} \cdot \mathrm{mol}^{-1}\right)$, hydrogen peroxide $\left(\mathrm{H}_{2} \mathrm{O}_{2}, 35 \mathrm{wt} \%\right)$, vitamin $\mathrm{C}$ or L-Ascorbic acid (AsA, $\geq 99.0 \%$ ), ammonium hydroxide $\left(\mathrm{NH}_{3} \cdot \mathrm{H}_{2} \mathrm{O}, 28-30 \mathrm{wt} \%\right)$ were supplied by Sigma-Aldrich. Graphene oxide (GO) aqueous dispersion with concentration of $4 \mathrm{mg} \cdot \mathrm{mL}^{-1}$ (>95\% monolayer conten, $\mathrm{pH} 2.2-2.5$ ).

Acid Green 25 (AG-25, $\mathrm{C}_{28} \mathrm{H}_{22} \mathrm{~N}_{2} \mathrm{NaO}_{8} \mathrm{~S}_{2}$ ) with molar mass $622.58 \mathrm{~g} \cdot \mathrm{mol}^{-1}$ (Sigma-Aldrich) were used as the model pollutant dye. The structural formula of the dye is presented in Fig. 1 . Deionized water (Milli-Q Millipore) was used throughout all the experiments.

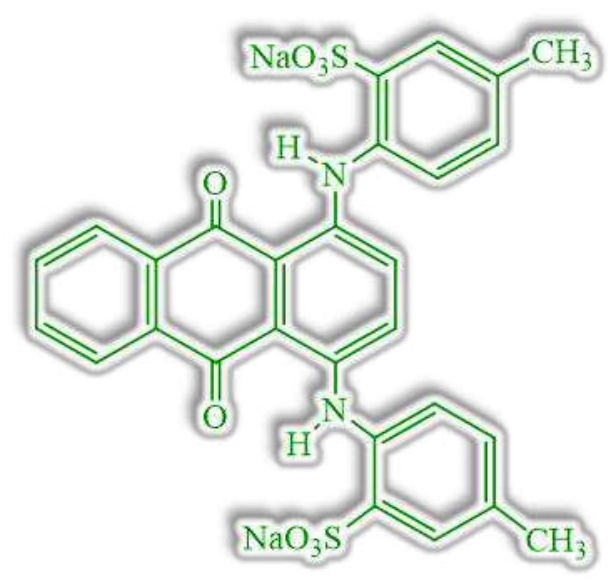

Figure 1. Chemical structure of AG-25 dye. 


\section{Preparation of 3D-rGO/Fe3 $\mathrm{O}_{4}$ nanostructures}

The nanocatalysts were prepared by simultaneous reduction of GO and the precursor for the magnetic nanoparticles $\mathrm{FeSO}_{4} \cdot 7 \mathrm{H}_{2} \mathrm{O}$ in colloidal aqueous dispersion at $90^{\circ} \mathrm{C}$. The process was performed either thermally or by combined thermal and chemical reduction using AsA as reducing agent.

An aqueous dispersion of $4 \mathrm{mg} \cdot \mathrm{mL}^{-1} \mathrm{GO}$ was ultrasonicated (Hielscher Sonicator -UIS250v) with an amplitude of $70 \%$ and energy pulsed at $0.5 \mathrm{~Hz}$ for $1 \mathrm{hr}$ at room temperature (RT). Then AsA was added to this dispersion (AsA : $\mathrm{GO}=1: 2$ ) and it was stirred for $30 \mathrm{~min}$ at room temperature (RT). This step was avoided when solely thermal reduction was used to produce the nanostructures. Afterwards, $0.2 \mathrm{M} \mathrm{FeSO}_{4} \cdot 7 \mathrm{H}_{2} \mathrm{O}$ was added (at molar ratio of $\mathrm{rGO}: \mathrm{Fe}_{3} \mathrm{O}_{4}$ $=1: 2$ ) and the $\mathrm{pH}$ was adjusted to 11 by dropwise addition of $\mathrm{NH}_{3} \cdot \mathrm{H}_{2} \mathrm{O}$. The obtained dispersion was transferred into an oven and kept at $90{ }^{\circ} \mathrm{C}$ for $2 \mathrm{~h}$ without stirring. As a result, a monolithic 3D composite structures $\mathrm{rGO} / \mathrm{Fe}_{3} \mathrm{O}_{4}$ were obtained. Often, instead of one monolith, a few smaller monolithic pieces were formed. The 3D water-swelled nanostructures were washed with DI water and frozen under liquid nitrogen, and subsequently freeze-dried (lyophilizated) for 3 days to remove completely the water, producing the 3D aerogel structures. 


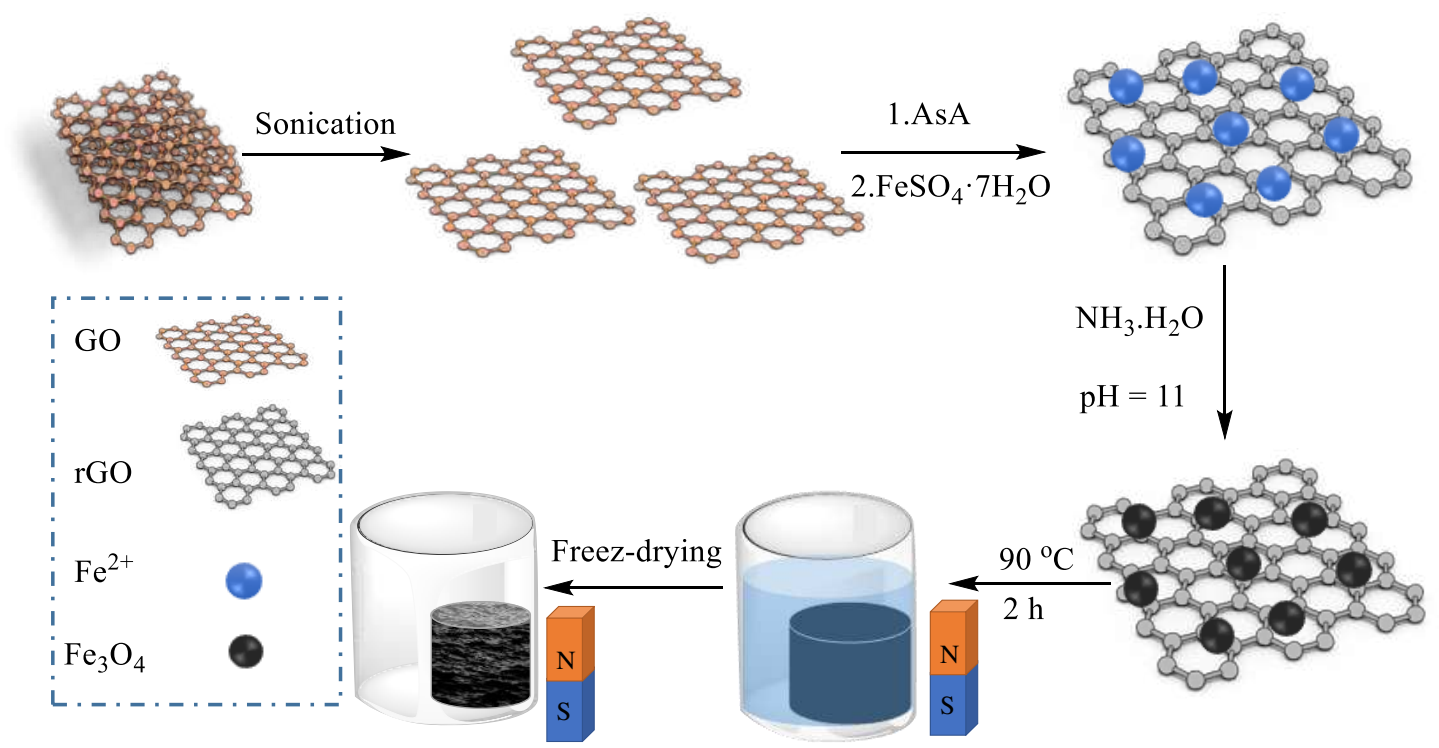

Figure 2. Schematic diagram of the preparation of the $3 \mathrm{D}-\mathrm{rGO} / \mathrm{Fe}_{3} \mathrm{O}_{4}$ nanostructures.

For comparison aim, the composite sample produced by reduction with AsA was dried as well conventionally in an oven at $50^{\circ} \mathrm{C}$ for $8 \mathrm{~h}$. The preparation process is schematically presented in Fig. 2. In one of the attempts, prior to reduction process PVP as shape controlling agent was added to investigate its effect on the porous structure and morphology. The reaction conditions are summarized in Table $\mathbf{1}$.

Table 1. Nomenclature of 3D materials and the conditions for their synthesis.

\begin{tabular}{ccccc}
\hline Nanocalatysts & GO: $\mathrm{Fe}_{3} \mathrm{O}_{4}$ & GO:AsA & PVP & Drying process \\
nomenclature & wt ratio & wt ratio & $\%$ & \\
\hline Neat 3D-rGO & - & $1: 2$ & - & Lyophilization \\
Th-rGO/Fe3O4/PVP & $1: 2$ & no AsA & $3 \%$ & Lyophilization \\
Ch-rGO/Fe $3 \mathbf{O}_{4}$ & $1: 2$ & $1: 2$ & - & $\begin{array}{c}\text { Lyophilization } \\
\text { and } 50^{\circ} \mathrm{C}, 8 \mathrm{~h}\end{array}$ \\
Th-rGO/Fe3O4 & $1: 2$ & no AsA & - & Lyophilization \\
\hline
\end{tabular}




\section{Characterization}

The 3D-rGO/ $/ \mathrm{Fe}_{3} \mathrm{O}_{4}$ nanocomposites were characterized by thermogravimetric analysis (TGA, TA Instruments Q500), by heating from $25^{\circ} \mathrm{C}$ to $800{ }^{\circ} \mathrm{C}$ at a rate of $10^{\circ} \mathrm{C} \cdot \mathrm{min}^{-1}$ under nitrogen. The morphology of the nanocomposites was evaluated using a Hitachi TM3030 tabletop Scanning Electron Microscope (SEM), equipped with energy dispersive X-ray (EDX) instrument at an accelerating voltage of $15 \mathrm{KV}$. The textural properties of the materials were studied by $\mathrm{N}_{2}$ adsorption isotherms measured at $-196^{\circ} \mathrm{C}$ with an ASAP 2020 instrument from Micromeritics. Before the analysis, the samples were degassed at $120^{\circ} \mathrm{C}$ for $5 \mathrm{~h}$. The surface area (SBET) was determined by the BET (Brunauer-Emmett-Teller) method. The total pore volume $(\mathrm{Vp})$ was determined from the amount of nitrogen adsorbed at $\mathrm{P} / \mathrm{P} 0=0.95$. The pore size distribution was analyzed by the BJH (Barrett-Joyner-Halenda) method from the adsorption branch of the isotherm and average pore diameter is obtained as Dpore $=4 \mathrm{~V} / \mathrm{SBET}$.

The crystalline phases were studied by X-ray diffraction (XRD) operating at a scanning rate of $10^{\circ} / \mathrm{min}$ from $10^{\circ}$ to $80^{\circ}$ (Philips $\mathrm{PW} 1730$ ) using $\mathrm{Cu} \mathrm{K} \alpha$ radiation. The magnetic properties of the nanoparticles have been examined using vibrating sample magnetometer (VSM, AGFM/VSM 3886).

To determine the surface chemistry of the 3D structures, XPS analyses were performed on a SPECS Sage HR 100 spectrometer with a non-monochromatic X-ray source (aluminium Ka line of $1486.7 \mathrm{eV}$ energy and $252 \mathrm{~W}$ ) placed perpendicular to the analyzer axis and calibrated using the $3 \mathrm{~d} 5 / 2$ line of Ag with a full width at half maximum (FWHM) of $1.1 \mathrm{eV}$. The selected spectra resolution was $15 \mathrm{eV}$ pass energy and $0.15 \mathrm{eV}$ per step. The measurements were performed at a pressure around $8 \times 10^{-8}$ mbar in an ultra-high vacuum chamber. For the Fe $2 \mathrm{p}$ and $\mathrm{Fe} 3 \mathrm{p}$ regions, the pass energy was $10 \mathrm{eV}$ with 15 acquisitions. 


\section{Removal of AG-25 from aqueous solution}

Using the composite 3D structures placed in AG-25 aqueous solution, two types of experiments were performed: simple dye adsorption and dye degradation. For both of these experiments, 3D nanostructure $(0.010$ and $0.020 \mathrm{~g})$ were placed in aqueous solutions of AG-25 with different dye concentration $\left(0.01-0.5 \mathrm{mg} \cdot \mathrm{mL}^{-1}\right)$. For dye degradation experiment $\mathrm{H}_{2} \mathrm{O}_{2}$ was added (2 $\mathrm{mL}$ of $0.01-0.05 \mathrm{M})$ to the aqueous solution containing already the $3 \mathrm{D}$ structure. The discoloration experiments were performed at $\mathrm{RT}$ at different $\mathrm{pH}$, changed in the range of 3 10. Samples of the aqueous solution were extracted at certain time intervals (5-180 min) and were analyzed by UV/Vis spectrophotometer at wavelength of $608 \mathrm{~nm}$ to determine the actual dye concentration.

After each experiment, the $3 \mathrm{D}-\mathrm{rGO} / \mathrm{Fe}_{3} \mathrm{O}_{4}$ adsorbent was separated by an external magnet and the final dye concentration was determined. The removal efficiency (R\%) of AG-25 by the nanocatalysts were calculated using Equation $(4)^{44}$.

$\% \mathrm{R}=\frac{\mathrm{C}_{0}-\mathrm{C}_{\mathrm{e}}}{\mathrm{C}_{0}} \times 100$

where $C_{o}$ and $C_{e}$ are the liquid phase initial and equilibrium concentrations of the AG-25 dye, respectively.

To demonstrate the dye degradation, MALDI-TOF-MS measurements were performed on a Bruker Autoflex Speed system (Bruker, Germany) equipped with a Smartbeam-II laser (Nd:YAG, 355nm, $2 \mathrm{kHz}$ ). Spectra were acquired in reflectron mode; each mass spectrum was the average of 10000 shots. The laser power was adjusted during the experiments. Each sample was characterized as received after the Fenton's reaction with AG-25 without using matrix. Approximately $0.5 \mu \mathrm{L}$ of the obtained solution was spotted by hand on the ground steel target plate and allowed to dry in air. 
Spectra were accumulated and processed using FlexControl (v3.4) and FlexAnalysis softwares (v3.4), respectively. Peaks were detected in SNAP mode with a signal-to-noise threshold of 3.00 before being processed with a Savitzky-Golay smoothing algorithm $(0.05 \mathrm{~m} / \mathrm{z}$ width, one cycle) and "TopHat" baseline subtraction. External calibration was performed in quadratic mode with a mixture of different polystyrene standards (PS, Varian).

\section{Results and discussion}

Under all investigated synthesis conditions shown in Table 1, 3D materials were produced. The 3D structure was formed due to a self-assembly of the GO platelets, which during reduction turned to be highly hydrophobic. Hence, they joined together in order to decrease the interfacial tension raised in the system due to chemical changes on the $\mathrm{rGO} .{ }^{45}$ The magnetic nanoparticles formed in situ were spontaneously incorporated within the structure. The magnetic nanoparticles nucleated onto the GO nanoplatelets and grow as the reduction progressed on the nanoplatelets' surface, as it was observed previously. ${ }^{35}$ In Fig. 3, the morphology determined by SEM of the 3D structures obtained by freeze-drying of the monoliths and their chemical composition determined by EDX are presented, including the EDX mapping. 
a)
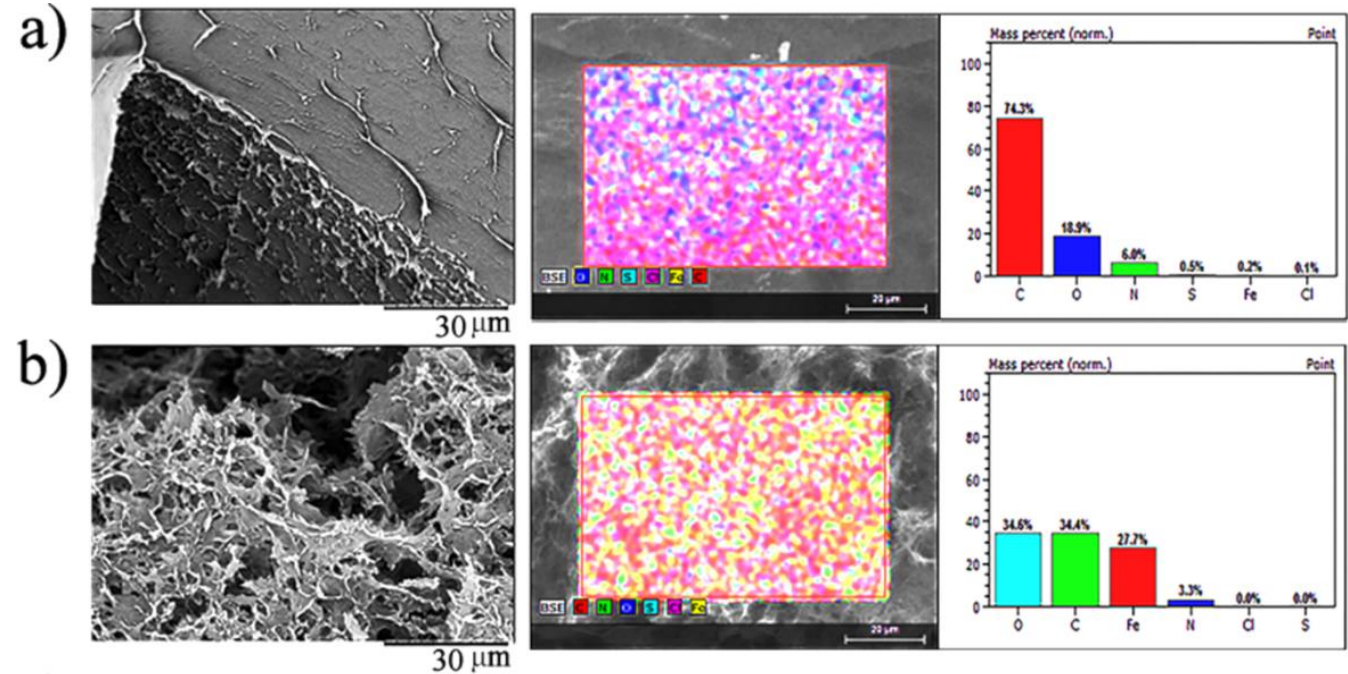

c)
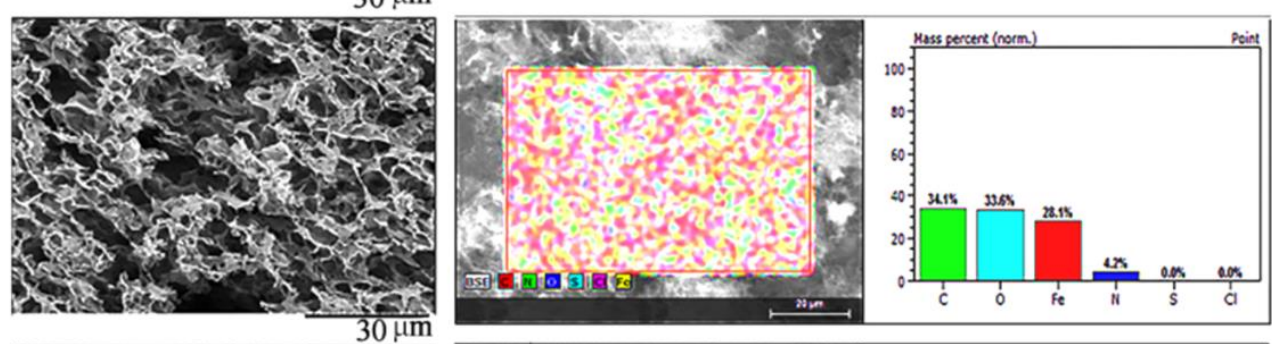

d)


Figure 3. Surface morphology, mapping and elemental composition of the 3D nanocomosites (a) Neat 3D-rGO; (b) Th-rGO/Fe $\mathrm{O}_{4} / \mathrm{PVP}$; (c) Ch-rGO/Fe $\mathrm{F}_{3}$; and (d) Th-rGO/Fe $\mathrm{O}_{4}$.

The SEM images in Figs. 3 (a-d) present porous 3D morphology of the nanocomposites. The neat 3D-rGO is rather compact 3D material at the scale shown in Fig. 3a. The presence of magnetic nanoparticles affected the morphology, which became more porous, presenting increasing number of micrometer pores, as it is shown in Figs. 3 (b-d). Similar effect was noticed in our previous work, which was assigned to the fact that magnetic nanoparticles attached on the rGO surface actuated as spacers and prevented complete re-aggregation of $\mathrm{rGO}$ platelets during the self-assembly. ${ }^{35}$ Therefore, the formed composite nanostructures are fluffier than the neat 3D-rGO. The elemental distribution mapping in Figs. 3(b-d) clearly 
demonstrates the presence of magnetic nanoparticles in the nancomposites (Fe element is denoted in red color), whereas in Fig. 3a one may observed the carbon reach surface (carbon is denoted in red in this image). The elemental compositions additionally demonstrated these evidences. Therefore, in neat-rGO nanostructure the material is composed roughly of about $74 \%$ carbon and $19 \%$ oxygen, with small nitrogen content probably coming from the ammonia used to adjust $\mathrm{pH}$. In the composite nanostructures, the relative quantities of carbon dropped importantly, giving rise of the Fe amount. However, the elemental composition between the nanocomposites is rather similar, which means that the employed conditions did not affected it. Moreover, in the EDX maps it may be observed that the magnetic nanoparticles are uniformly distributed all over the rGO matrix.

It is worth noting that the 3D hydrogel structure was freeze-dried because it was noticed that in case of conventional heating, the volume of the conventionally (oven) dried composite (Ch$\mathrm{rGO} / \mathrm{Fe}_{3} \mathrm{O}_{4}$ ) was considerably lower than the volume of the lyophilized nanostructures and presented peculiar flower morphology, as it is shown in Fig. 4. The oven-drying process had notable effect on the morphology, too, as can be seen in Fig. 4, flower morphology was obtained in this case, made of highly wrinkled rGO nanoplatelets. This material was not further investigated, due to the very rigid nature and difficult handling, as the $3 \mathrm{D}$ structures dried conventionally were not stable, and we show them because of the peculiar morphology, which may surge different type of application. 


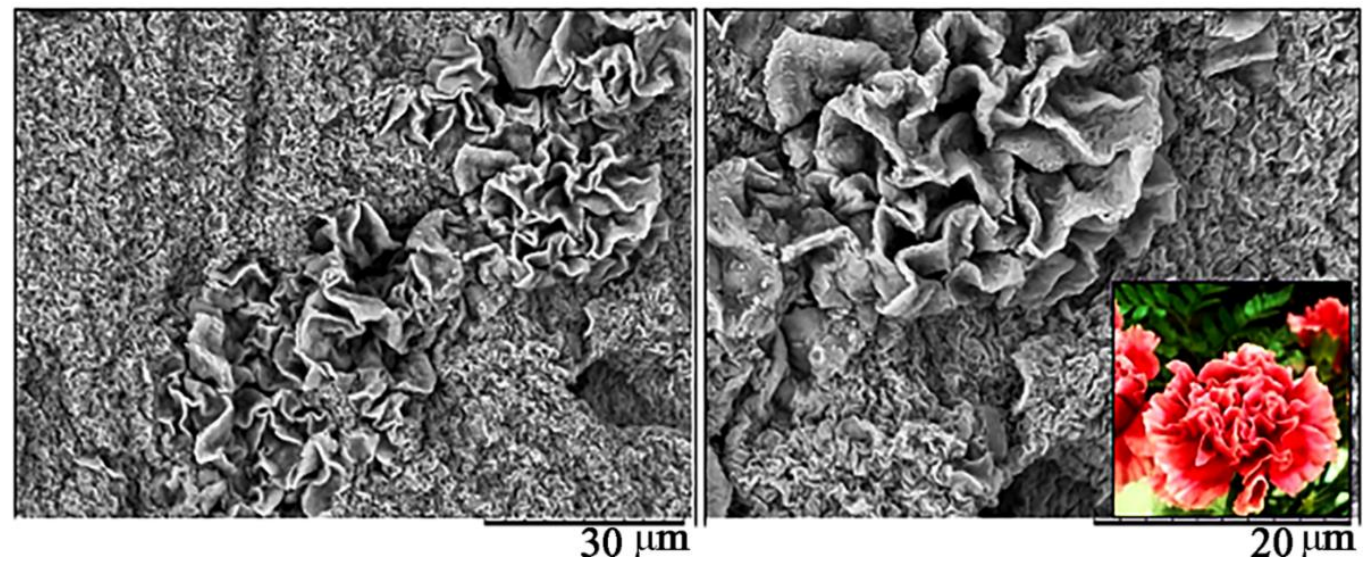

Figure 4. SEM micrographs of $\mathrm{Ch}-\mathrm{rGO} / \mathrm{Fe}_{3} \mathrm{O}_{4}$ nanostructure obtained by heat-drying under lower (left) and higher (right) magnification. The inset in the right image show a photo of flower with similar structuring.

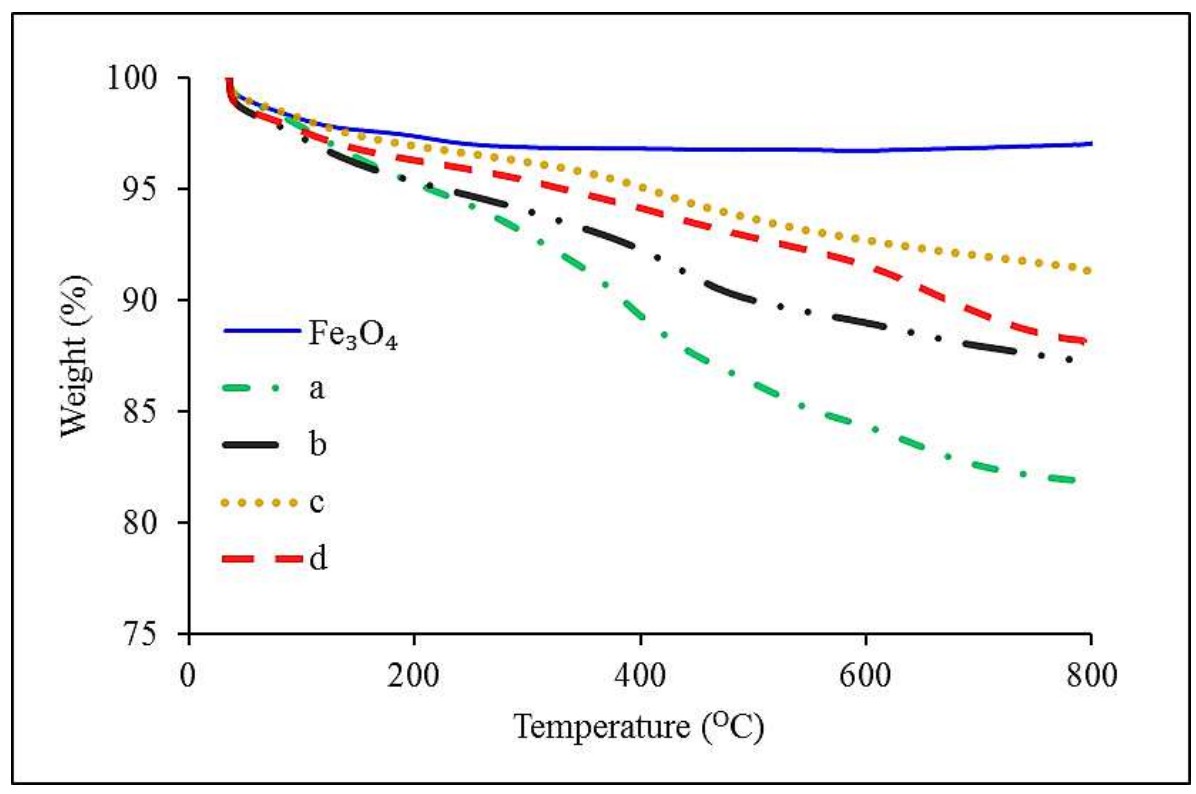

Figure 5. TGA results of neat $\mathrm{Fe}_{3} \mathrm{O}_{4}$ nanoparticles; (a) neat3D- rGO; (b) Th-rGO/Fe $3 \mathrm{O}_{4} / \mathrm{PVP}$; (c) Ch$\mathrm{rGO} / \mathrm{Fe}_{3} \mathrm{O}_{4}$; and (d) $\mathrm{Th}-\mathrm{rGO} / \mathrm{Fe}_{3} \mathrm{O}_{4}$.

The 3D structures were analyzed by TGA to determine the thermal stability of the nanocomposites and to obtained additional information on the structure and interaction within the composites. Fig. 5 shows the weight loss curves obtained by TGA of the neat $\mathrm{Fe}_{3} \mathrm{O}_{4}$ nanoparticles, the neat 3D-rGO and the nanocomposite materials. The TGA study shows that the nanocomposite structures present thermal stability and thermal degradation behavior 
between the both neat components rGO and magnetic nanoparticles. The synthesis conditions influence the thermal stability.

The most thermally stable composite is $\mathrm{Ch}-\mathrm{rGO} / \mathrm{Fe}_{3} \mathrm{O}_{4}$, obtained by simultaneous chemical and thermal reduction. The synthesis performed by both AsA and temperature is likely the reason for the improved thermal stability, because it provides conditions for faster reduction process, resulting in sudden confluence of the nanoplatelets and substantially more compact structure formation. Consequently, the more compact structure needed more energy to be thermally degraded. The thermally weakest structure was the one obtained in presence of PVP, which is a colloidal stabilizer. When adsorbed on the surface of rGO platelets, PVP decreases the interface tension between $\mathrm{rGO}$ and water, which is likely the driving force for the nanoplatelets confluence. Therefore, the resulting structure is less compact and easier to be thermally degraded.

The specific surface area of the nanocomposite is important properties that influences the adsorption and catalytic capability. It depends on the textural properties of the nanocomposites, which were determined from the $\mathrm{N}_{2}$ adsorption-desorption isotherms, presented in Fig. 6. 


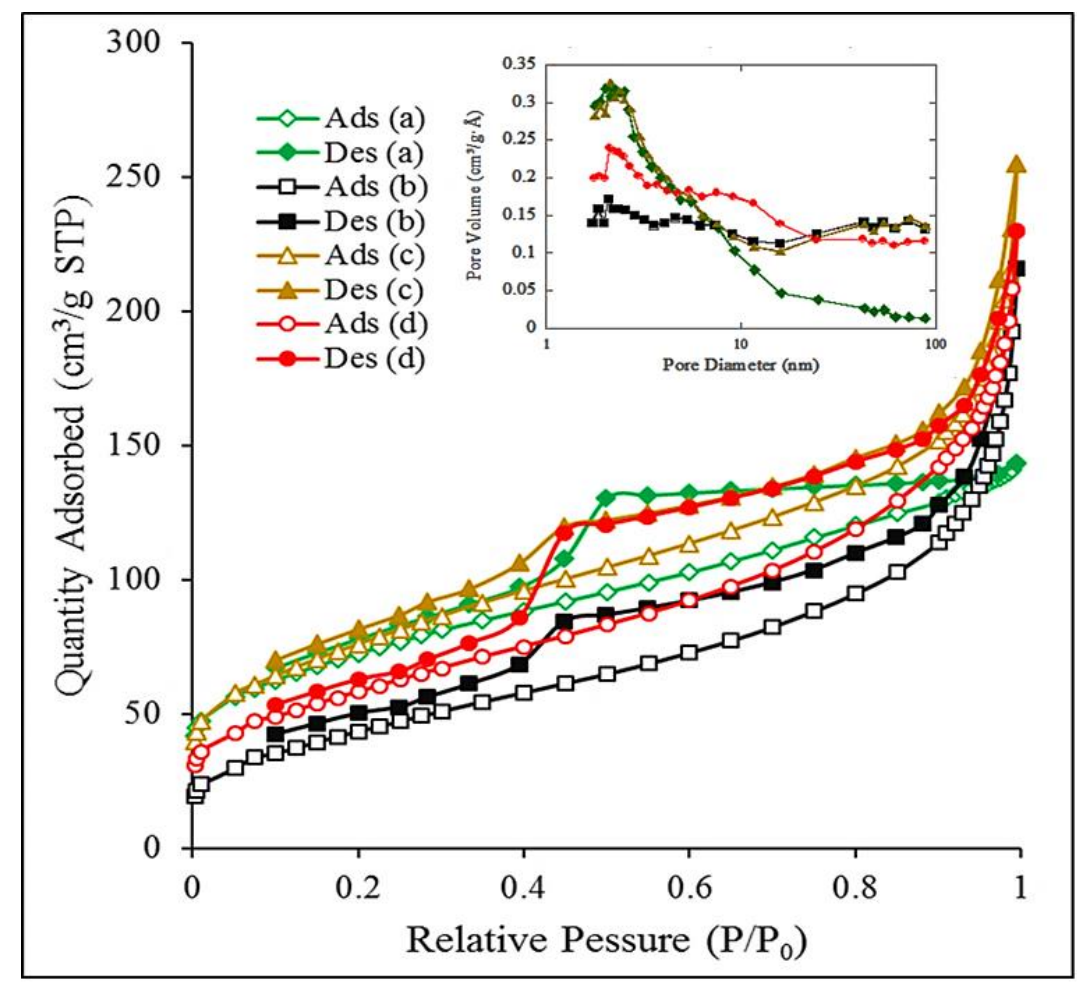

Figure 6. Adsorption-desorption isotherm of $\mathrm{N}_{2}$ (inset shows pore size distribution) of (a) neat 3DrGO; (b) Th-rGO/Fe $\mathrm{O}_{4} / \mathrm{PVP}$; (c) Ch-rGO/Fe $\mathrm{O}_{4}$; and (d) Th-rGO/Fe $\mathrm{O}_{4}$. In the inset, pore size distributions of the same materials are presented.

The isotherms shown in Fig. 6 are of type IV (IUPAC classification ${ }^{46}$ ), indicating that the nanostructures are mesoporous. The existence of hysteresis loop between adsorption desorption processes accounts for irregular pore shapes in which capillary condensation phenomenon occurred. ${ }^{47}$ The textural properties of the nanocomposites are presented in Table 2. They correspond to the indication obtained from TGA analysis. The highest BET surface area was obtained for neat 3D-rGO and for $\mathrm{Ch}-\mathrm{rGO} / \mathrm{Fe}_{3} \mathrm{O}_{4}$, both of them obtained by combined chemical (AsA) and thermal reduction. Addition of magnetic nanoparticles negatively influenced the porous structure, as the average diameter of the pores increased, likely because the nanoparticles adsorbed strongly on the rGO nanoplatelets, acting as a spacer in moment of nanoplatelets stacking, but as well making the nanoplatelts more rigid. Consequently, they formed larger pores between 10-100 nm (larger distance between the nanoplatelets) (Fig. 6, 
inset). If we compare the neat $3 \mathrm{D}-\mathrm{rGO}$ and $\mathrm{Ch}-\mathrm{rGO} / \mathrm{Fe}_{3} \mathrm{O}_{4}$, which were obtained exactly under the same conditions, the presence of $\mathrm{Fe}_{3} \mathrm{O}_{4}$ nanoparticles affected positively the porosity, as higher pore volume was obtained, resulting in the largest BET surface area obtained in this work of about $266 \mathrm{~m}^{2} \cdot \mathrm{g}^{-1}$ (Table 2). In addition, this preparation method allows maintaining the pores of the 3D-rGO. This may be result on a less rGO platelets aggregation in presence of magnetic nanoparticles, thus the walls of the pores are thicker in the neat rGO structure, which decrease its specific surface area. SEM image (Fig. 3a) demonstrates this additionally.

When the nanostructures were synthesized solely by thermal reduction, in both cases the composite structures are more porous than the neat 3D-rGO. Nevertheless, the porosity decreased with respect to $\mathrm{Ch}-\mathrm{rGO} / \mathrm{Fe}_{3} \mathrm{O}_{4}$, resulting in lower BET of $204 \mathrm{~m}^{2} \cdot \mathrm{g}^{-1}$ for Th$\mathrm{rGO} / \mathrm{Fe}_{3} \mathrm{O}_{4}$ and $164 \mathrm{~m}^{2} \cdot \mathrm{g}^{-1}$ for Th-rGO/Fe $\mathrm{O}_{4} / \mathrm{PVP}$, due to an important decrement of $1-10 \mathrm{~nm}$ of the pore diameter (Fig. 6, inset). The presence of PVP in such case, furthermore affected negatively the textural properties.

Table 2. Textural properties of the nanostructures.

\begin{tabular}{cccc}
\hline Nanocalatysts & $\begin{array}{c}\text { Surface Area } \\
\left(\mathbf{m}^{\mathbf{2}} \cdot \mathbf{g}^{-1}\right)\end{array}$ & $\begin{array}{c}\text { Pore Volume } \\
\left(\mathbf{c m}^{\mathbf{3}} \cdot \mathbf{g}^{-1}\right)\end{array}$ & $\begin{array}{c}\text { Average Pore } \\
\text { Size }(\mathbf{n m})\end{array}$ \\
\hline 3D-rGO & 258 & 0.22 & 3 \\
Th-rGO/Fe $3 \mathbf{O}_{4} / \mathbf{P V P}$ & 164 & 0.33 & 8 \\
Ch-rGO/Fe $3 \mathbf{O}_{4}$ & 266 & 0.40 & 5 \\
Th-rGO/Fe $_{3} \mathbf{O}_{4}$ & 204 & 0.35 & 6 \\
\hline
\end{tabular}

Based on the thorough characterization of the developed composites, Ch-rGO/Fe ${ }_{3} \mathrm{O}_{4}$ was selected for the study of the discoloration process of AG-25 aqueous solution. Prior to the 
discoloration study, the chemical composition of $\mathrm{Ch}-\mathrm{rGO} / \mathrm{Fe}_{3} \mathrm{O}_{4}$ was examined by XPS to determine the $\mathrm{rGO}$ - Fe bonding, since it may be decisive for the catalytic activity.


Figure 7. XPS spectra of Ch-rGO/Fe $\mathrm{O}_{3}$ (a) $\mathrm{C} 1 \mathrm{~s}$ and (b) $\mathrm{O}$ 1s core level spectra.

In Fig. 7a, the $\mathrm{C} 1 \mathrm{~s}$ region after the deconvolution shows that the main contribution originates from $\mathrm{sp}^{2} \mathrm{C}$, the peak centered at $284.6 \mathrm{eV}$ and lesser quantity of C-O-C at $286.1 \mathrm{eV}$, followed by few contributions of $\mathrm{C}-\mathrm{O}, \mathrm{C}=\mathrm{O}, \mathrm{CO}_{3}{ }^{-2}$ and $\mathrm{O}-\mathrm{C}=\mathrm{O}$. No evidence of $\mathrm{Fe}-\mathrm{C}$ bonding was observed. The wide peak observed in Fig. 7b denoting $\mathrm{O}$ 1s region displays the major presence of C-O, some oxygen from humidity and a peak observed at $530.9 \mathrm{eV}$, assigned to the $\mathrm{Fe}-\mathrm{O}-$ $\mathrm{C}$ bond. The presence of this peak demonstrates that the magnetic nanoparticles were strongly bonded to the 3D rGO structure by covalent bond established between graphene and magnetic nanoparticles through oxygen. This bond has been observed already in similar structures, ${ }^{35,48}$ and was obviously promoted by the in situ creation of the $\mathrm{Fe}_{3} \mathrm{O}_{4} \mathrm{NP}$. The proposed routes toward establishing of this structure are based on either replacement of hydrogen atom in the carboxylic group by bidentate coordination with an iron atom, or iron catalyzed ring opening reaction of epoxy groups. ${ }^{48}$ 
The XRD patterns of rGO and Ch-rGO/Fe $3 \mathrm{O}_{4}$ were presented in Fig. 8. As shown in Fig. 8a, a broad peak appeared at about $25.81^{\circ}$ corresponds to the (002) plane of rGO. The diffraction peaks observed in Fig. 8b, centered at $2 \theta$ of 29.34, 35.71, 36.25, 43.82, 53.87, 57.40, and $63.13^{\circ}$ can be assigned to (220), (311), (222), (400), (422), (511), and (440) reflections, respectively for $\mathrm{Fe}_{3} \mathrm{O}_{4}$ in Ch-rGO/Fe $\mathrm{O}_{4}$ nanostructure (JCPDS No. 72-2303). ${ }^{49,50}$

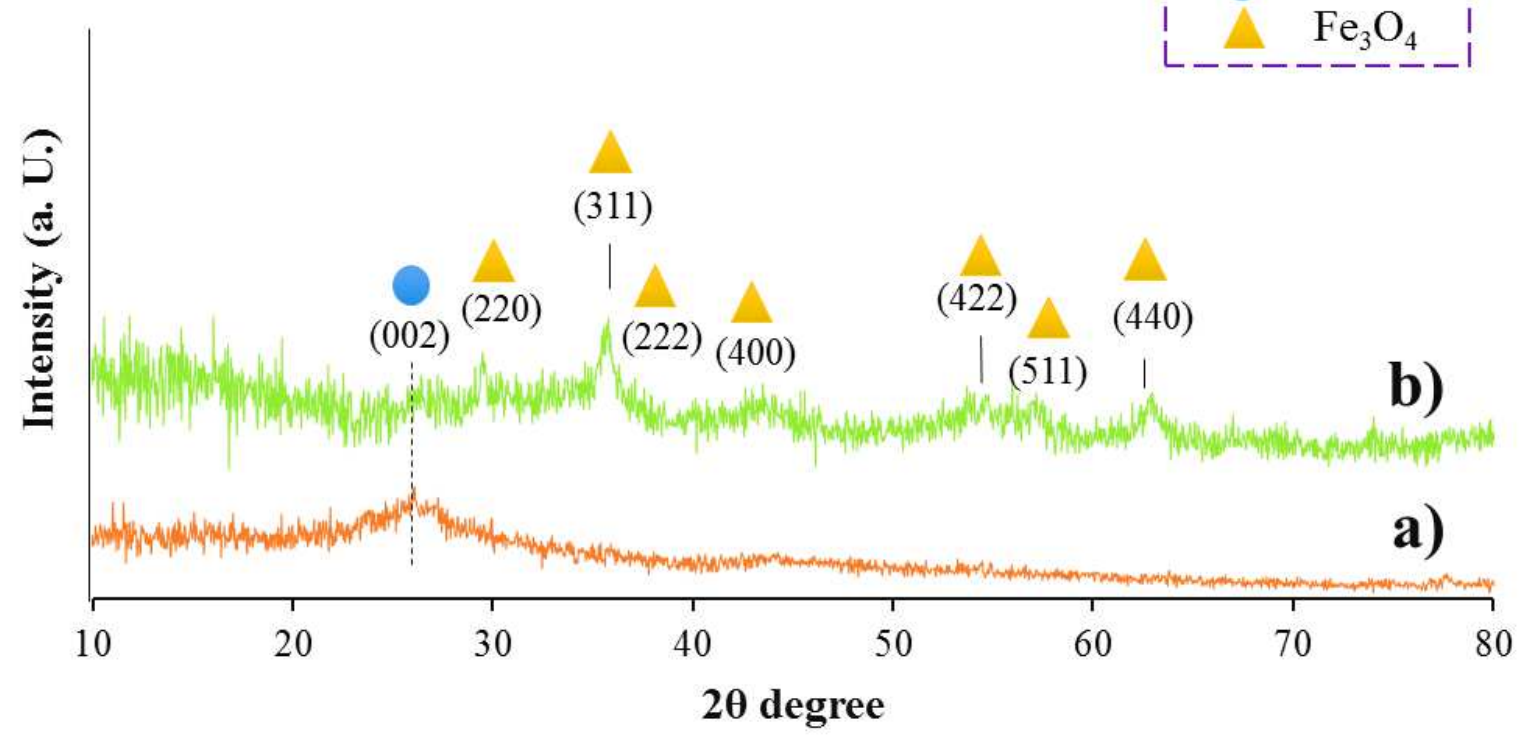

Figure 8. XRD patterns of (a) neat $\mathrm{rGO}$ and (b) $\mathrm{Ch}-\mathrm{rGO} / \mathrm{Fe}_{3} \mathrm{O}_{4}$.

The magnetization hysteresis loops of curves of $\mathrm{Fe}_{3} \mathrm{O}_{4}$ and $\mathrm{Ch}-\mathrm{rGO} / \mathrm{Fe}_{3} \mathrm{O}_{4}$ were measured by VSM at room temperature. From Fig. 9, it is evident that the saturation magnetization values for $\mathrm{Fe}_{3} \mathrm{O}_{4}$ and $\mathrm{Ch}-\mathrm{rGO} / \mathrm{Fe}_{3} \mathrm{O}_{4}$ nanocatalyst were $\sim 58 / 20$ and $24 \mathrm{emu} \cdot \mathrm{g}^{-1}$, respectively, which demonstrate the magnetic properties of the nanoparticles distributed within $3 \mathrm{D}$ rGO structure. ${ }^{51}$ 


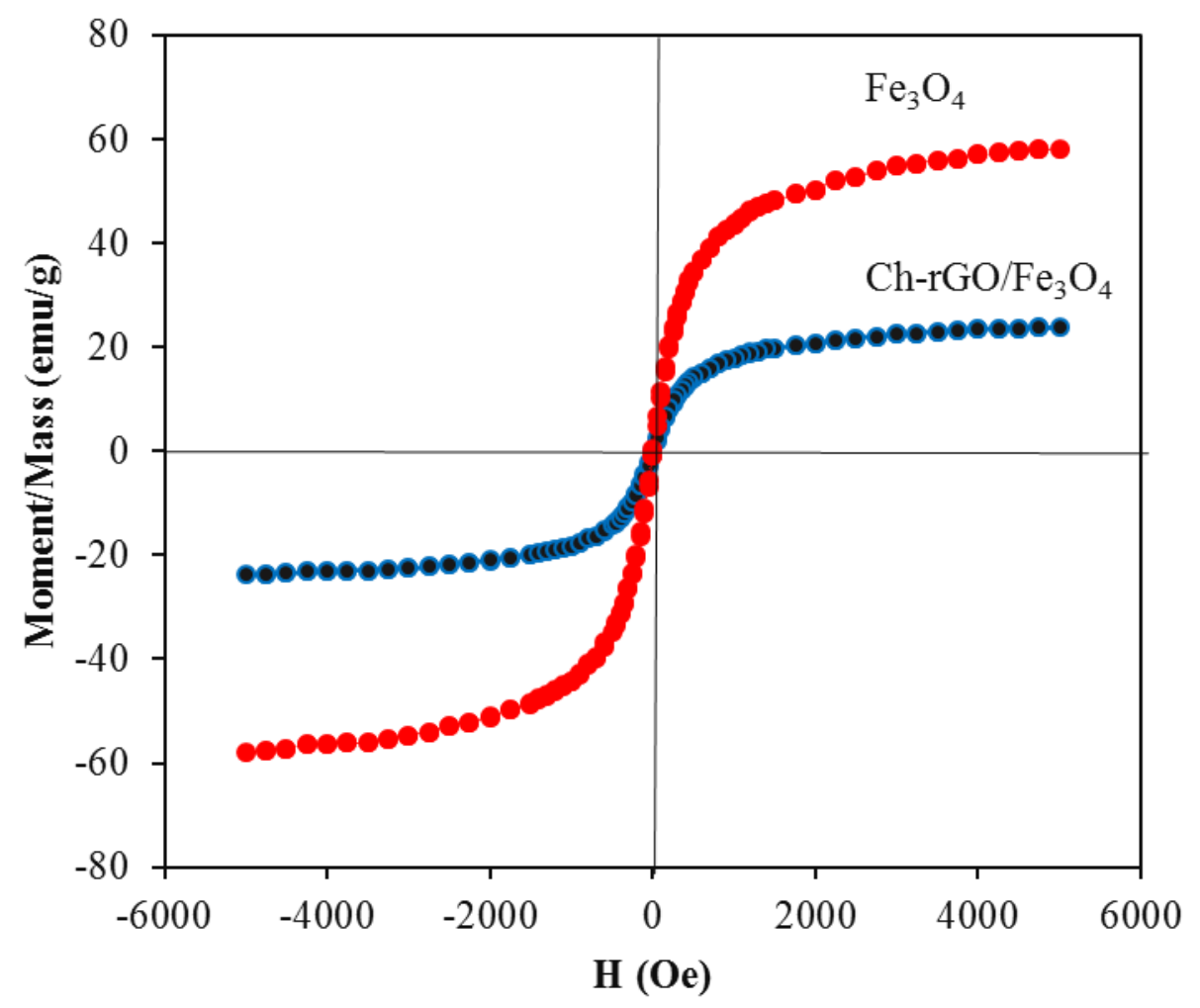

Figure 9. Magnetization curves of $\mathrm{Fe}_{3} \mathrm{O}_{4}$ and $\mathrm{Ch}-\mathrm{RGO} / \mathrm{Fe}_{3} \mathrm{O}_{4}$ at room temperature.

\section{Discoloration of AG-25 aqueous solutions by adsorption}

The 3D structured monolith $\mathrm{Ch}-\mathrm{rGO} / \mathrm{Fe}_{3} \mathrm{O}_{4}$ was used as adsorbent and nanocatalyst for $\mathrm{AG}-25$ azo dye elimination from model polluted aqueous solutions. The effect of dye concentration, $\mathrm{pH}$, and adsorbent dose were studied to find out the optimal conditions. In the first part of the study of discoloration ability of the Ch-rGO/Fe ${ }_{3} \mathrm{O}_{4} 3 \mathrm{D}$ material, the investigation was focused on adsorption of the AG-25 azo organic dye. It was compared with neat 3D-rGO. Fig. 10 shows the schematic illustration of the adsorption process for the AG-25 using Ch-rGO/ $\mathrm{Fe}_{3} \mathrm{O}_{4}$. 


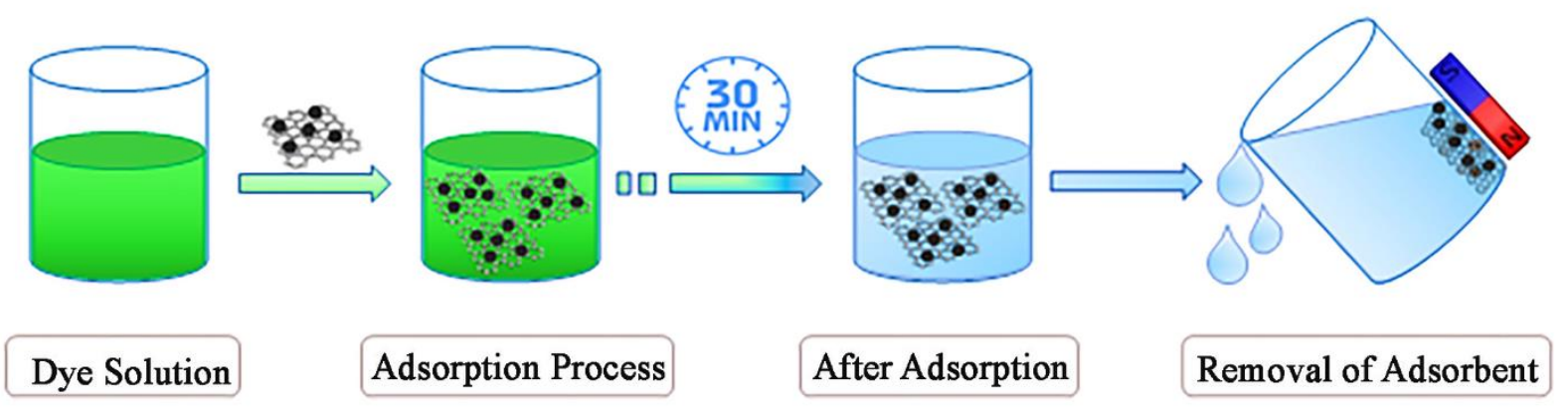

Figure 10. Schematic illustration of the adsorption process for the AG-25 using Ch-rGO/Fe ${ }_{3} \mathrm{O}_{4}$.

According to Fig. 10, $0.010 \mathrm{~g}$ of $\mathrm{Ch}-\mathrm{rGO} / \mathrm{Fe}_{3} \mathrm{O}_{4}$ or 3D-rGO nanostructures were placed in the AG-25 aqueous solution with dye concentration of $0.5 \mathrm{mg} \cdot \mathrm{mL}^{-1}$ without adjusting of the $\mathrm{pH}$. As it is shown in Fig. 11, for composite nanostructure $\mathrm{Ch}-\mathrm{rGO} / \mathrm{Fe}_{3} \mathrm{O}_{4}$ complete discoloration occurred in $30 \mathrm{~min}$, whereas neat 3D-rGO nanostructure needed 60 min to discolor completely the solution. The enhanced performance of the composite nanostructure is due to the increased porosity and the contribution of very small pores to the larger specific surface area offered by the $\mathrm{Ch}-\mathrm{rGO} / \mathrm{Fe}_{3} \mathrm{O}_{4}$ for capture of the dye molecules. The inset in Fig. 11 shows the photos of the discoloration process: (1) presents the initial dye solution; (2) presents the same solution after addition of nanocomposite catalyst; and (3) presents the effective and easy separation of the nanostructure from the aqueous solution after complete discoloration by external magnet. 


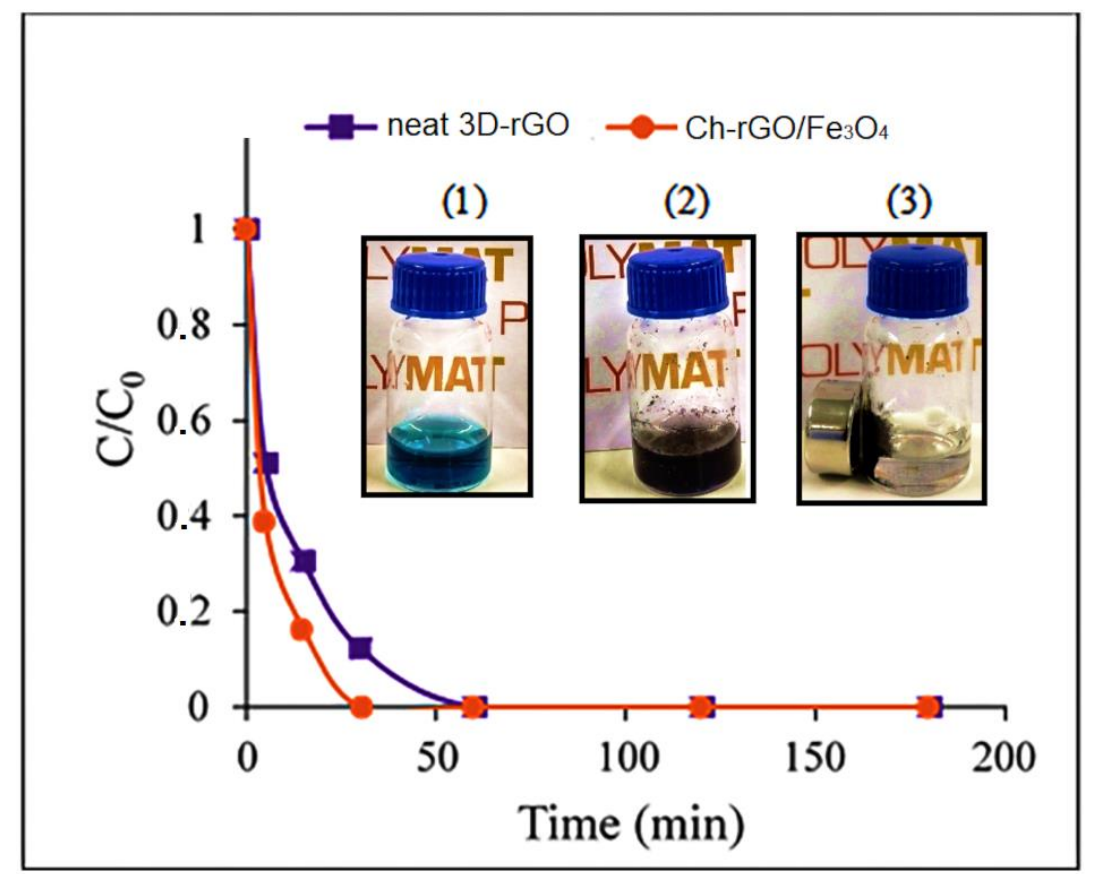

Figure 11. Effect of adsorbent kind on adsorption of AG-25 by neat $\mathrm{rGO}$ and $\mathrm{Ch}-\mathrm{rGO} / \mathrm{Fe}_{3} \mathrm{O}_{4}$.

Experimental conditions: adsorbent dosage $0.010 \mathrm{~g}$, dye concentration $0.01 \mathrm{mg} \cdot \mathrm{mL}^{-1}, \mathrm{RT}$, and natural $\mathrm{pH}$; Inset: Photos of the discoloration process and separation of the nanostructure afterward.

Fig. 12, presents the kinetic curves and the process efficiency as a function of the dye concentration, studied in the range of $0.01-0.5 \mathrm{mg} \cdot \mathrm{mL}^{-1}$ at constant amount of composite nanostructure $\mathrm{Ch}-\mathrm{rGO} / \mathrm{Fe}_{3} \mathrm{O}_{4}(0.010 \mathrm{~g})$. The adsorption rate dropped importantly at higher dye concentration (Fig. 12a), as well as the removal efficiency (Fig. 12b). With the studied amount of nanostructure, the maximum concentration of the dye until which the process is efficient ( $100 \%$ removal rate) is $0.04 \mathrm{mg} \cdot \mathrm{mL}^{-1}$. In case of as high dye concentration as $0.5 \mathrm{mg} \cdot \mathrm{mL}^{-1}$, the process efficiency is about $26 \%$. The performance decreased likely because of the saturation of the adsorption sites with the dye molecules as its concentration increased. The adsorption rate initially is very high and similar for all the dye concentration, however, as the surface of the adsorbents became saturated, the rate dropped substantially. This drop is larger for larger dye concentration. Afterwards, the kinetic curves present saturation of the adsorbent and no further dye adsorption. This indicates that the process should be optimized further. 

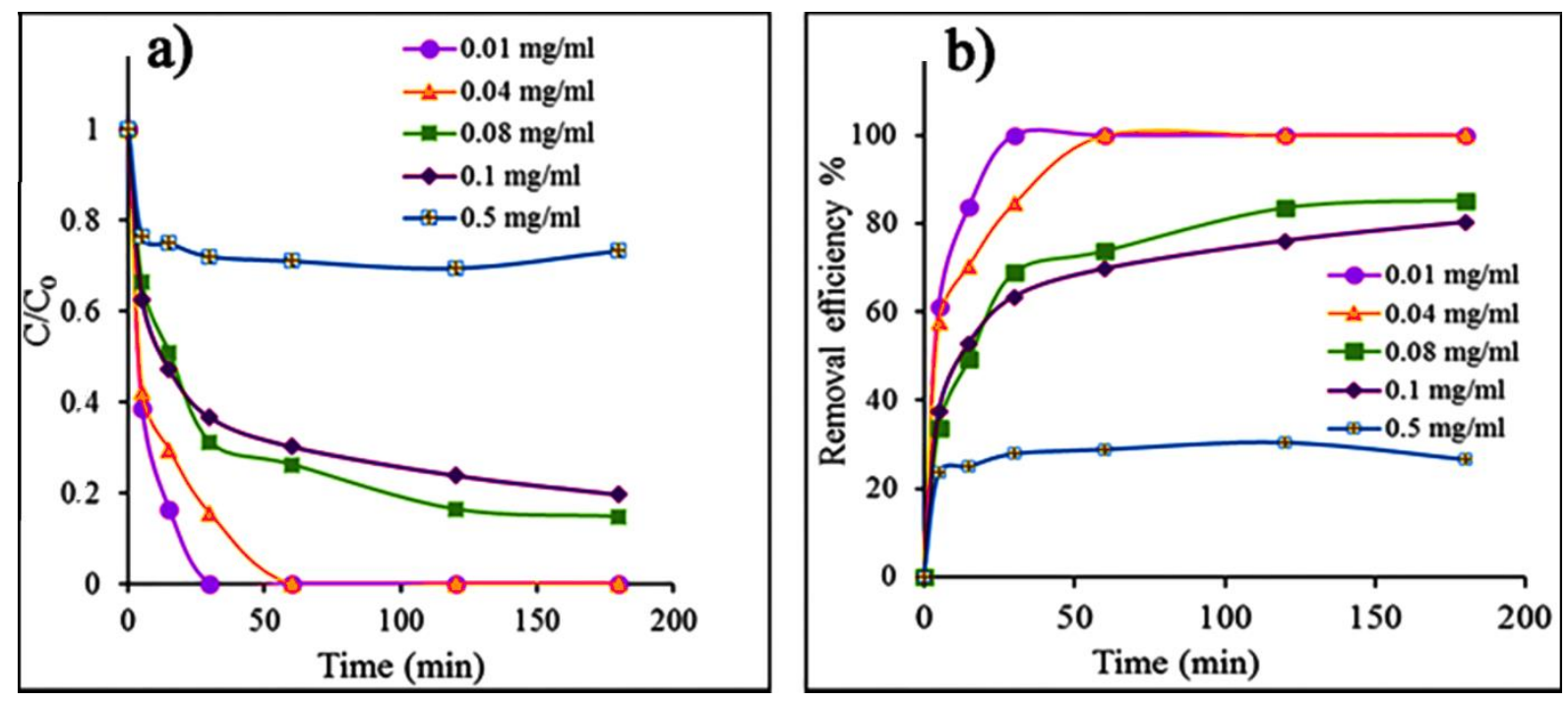

Figure 12. Effect of initial dye concentration on adsorption of $\mathrm{AG}-25$ by $\mathrm{Ch}-\mathrm{rGO} / \mathrm{Fe}_{3} \mathrm{O}_{4}$.

Experimental conditions: adsorbent dose $0.010 \mathrm{~g}, \mathrm{RT}$, and natural $\mathrm{pH}$.

It is well known that the Fenton reaction, for maximum performance, should be performed at $\mathrm{pH}$ in a range of $3-4$, because at higher $\mathrm{pH}$ the iron precipitates in a form of hydroxide. ${ }^{39-42}$ This means that there is a loss of valuable ferrous ions and $\mathrm{H}_{2} \mathrm{O}_{2}$, turning the reaction inefficient. However, this is so if homogeneous Fenton reactions are considered. In case of the heterogeneous process, the $\mathrm{pH}$ of the solution additionally affects the interactions adsorbentdye, because the $\mathrm{pH}$ determines the adsorbent surface charge, degree of ionization of pollutant, separation of functional groups on the active sites of the adsorbent as well as the structure of the dye molecule. If the interaction conditions are unfavorable, there will be less or no contact between the dye molecule and the magnetic nanoparticle catalysts. Therefore, it would be of great importance to study these interactions conditions at different $\mathrm{pH}$. To distinct them from the Fenton reaction effects, the influence of $\mathrm{pH}$ was studied in absence of $\mathrm{H}_{2} \mathrm{O}_{2}$.

In case of $0.1 \mathrm{mg} \cdot \mathrm{mL}^{-1}$ dye concentration, the maximum achieved adsorption efficiency using $0.010 \mathrm{~g}$ adsorbent was close to $80 \%$. This efficiency was obtained at natural $\mathrm{pH}$ of the dispersion without any adjusting. The adsorption process was then studied in $\mathrm{pH}$ range of 3 10. Fig. 13 shows the effect of $\mathrm{pH}$ on the adsorption efficiency of $\mathrm{AG}-25$ by $\mathrm{Ch}-\mathrm{rGO} / \mathrm{Fe}_{3} \mathrm{O}_{4}$. 



Figure 13. Effect of $\mathrm{pH}$ on the adsorption of $\mathrm{AG}-25$ by $\mathrm{Ch}-\mathrm{rGO} / \mathrm{Fe}_{3} \mathrm{O}_{4}$. Experimental conditions: adsorbent contact time $180 \mathrm{~min}$, dye concentration $0.1 \mathrm{mg} \cdot \mathrm{mL}^{-1}$, RT, and adsorbent dose $0.010 \mathrm{~g}$. $\mathrm{pH}$ augmentation from 3 to 10 affects adversely the adsorption process, thus, the AG-25 adsorption efficiency dropped from about $98 \%$ at $\mathrm{pH}=3$ to as low as $40 \%$ for $\mathrm{pH}=10$. Considering that there are some carboxylic functionalities onto the surface of the rGO based structure, at $\mathrm{pH}=3$, which is lower than $\mathrm{pKa}=4$ of carboxylic acids, ${ }^{52}$ most of them will be in protonated form. However, in such conditions the sulfonic acid groups in AG-25 are in anionic form, as their $\mathrm{pKa}$ is $2.8,{ }^{53}$ which promotes ion-dipole interactions between sulfonic anion and carboxylic group. Likely, by increasing the $\mathrm{pH}$, carboxylic groups are turned into deprotonated (anionic) form and electrostatic repulsions occurs between the graphenic carboxylic anion and the anionic sulfonic acid groups in the dye, resulting in drop of the adsorption amounts, as shown in Fig. 13. In such case, only the interactions of the neat graphenic areas on the 3D structures with aromatic conjugated structure of AG-25 dye likely build $\pi-\pi$ interactions with graphene. This results in a removal efficiency in a range of $60 \%-40 \%$, and likely will affect Fenton reaction, making it slower and less efficient.

For the specific chemistry of the selected organic dye AG-25 and rGO structure, the pH of 3 has shown maximum removal efficiency. This result would be probably being affected if other type of chemistry for adsorbent and dye is selected. However, it seems that the best performance 
$\mathrm{pH}$ for the adsorbent - dye interactions cross the threshold of the suggested $\mathrm{pH}$ range for the best performance of magnetic nanoparticles as Fenton catalyst.

Furthermore, the effect of the adsorbent dose on the adsorption capacity and the removal efficiency was studied, at $\mathrm{pH}=3$. For that aim, the amount of the adsorbent used $(0.010 \mathrm{~g})$ was duplicated $(0.02 \mathrm{~g})$. The kinetic curves and the removal efficiency are compared in Fig. 14 (a and $b)$.
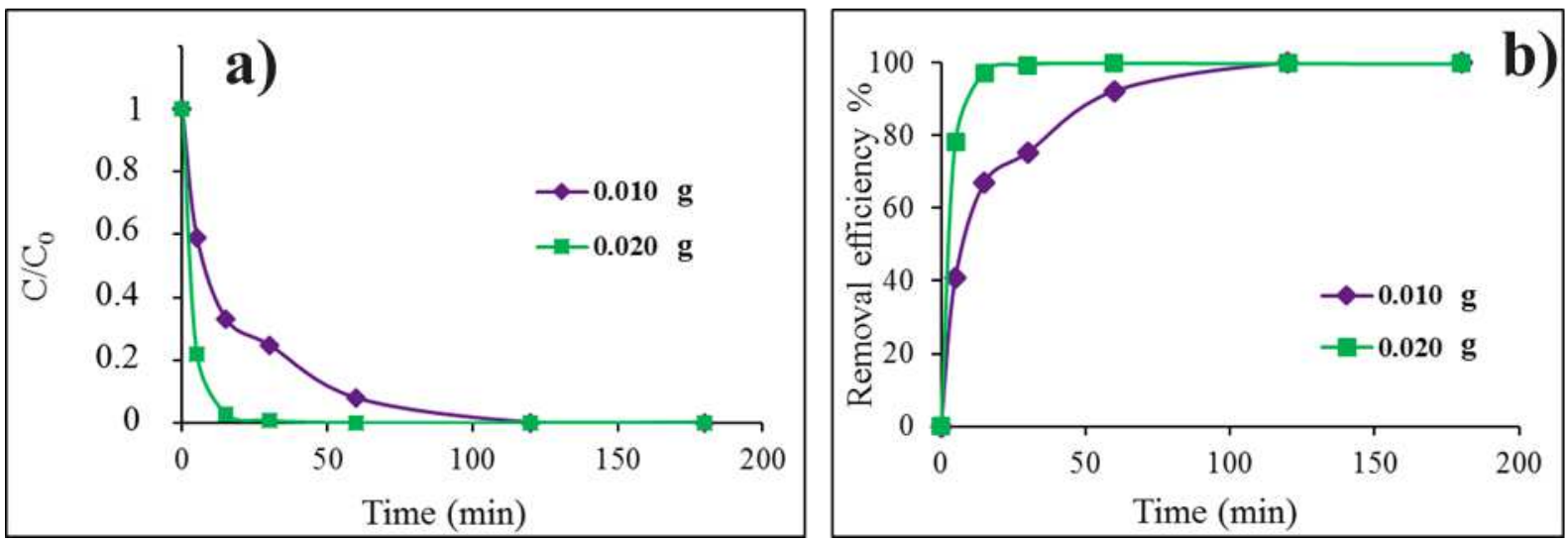

Figure 14. Effect of adsorbent dosage on the adsorption of $\mathrm{AG}-25$ by $\mathrm{Ch}-\mathrm{rGO} / \mathrm{Fe}_{3} \mathrm{O}_{4}$. Experimental conditions: dye concentration $0.1 \mathrm{mg} \cdot \mathrm{mL}^{-1}, \mathrm{RT}$, and $\mathrm{pH}=3$.

Fig. 14 showed that the solution of AG-25 dye with concentration of $0.1 \mathrm{mg} \cdot \mathrm{mL}^{-1}$ was discolored in $2 \mathrm{~h}$ by $0.010 \mathrm{~g}$ adsorbent. However, when double amount of adsorbent was used, the removal time was decreased to less than $30 \mathrm{~min}$, for which the efficiency is $100 \%$. It is worth mentioning that the removal efficiency of this reaction was noticeable augmented, as it is similar to the removal efficiency presented in Fig. 12 obtained for one order of magnitude more diluted dye solutions $\left(0.01 \mathrm{mg} \cdot \mathrm{mL}^{-1}\right)$. The last result is due to the doubled amount of adsorbent that offers much more adsorption sites and due to the $\mathrm{pH}$ of 3 that promoted dyeadsorbent interactions. 


\section{Mechanism of the AG-25 adsorption by $3 \mathrm{D}$ rGO/Fe $3 \mathrm{O}_{4}$ composite nanostructure}

The proposed adsorption mechanism is presented in Fig. 15. The aromatic conjugated structure of AG-25 dye provides opportunity of building of strong $\pi-\pi$ interactions with graphene. Neat graphenic areas in the studied 3D materials provide a base for establishing of these interactions. However, the presence of functional groups on graphene surface, the ionic state of which can be tailored by the $\mathrm{pH}$ of the solution, provides further adsorption sites, by establishing ionic interactions with the dye molecule. An acidic $\mathrm{pH}$ of 3 was found to have determining effect on the dye adsorption. Obviously, the $\mathrm{pH}$ should be adjusted to be in-between that of $\mathrm{pKa}$ of graphene carboxylic groups and $\mathrm{pKa}$ of sulfonic acid group of AG-25 to maximize the adsorption capacity of the $3 \mathrm{D}$ structure.

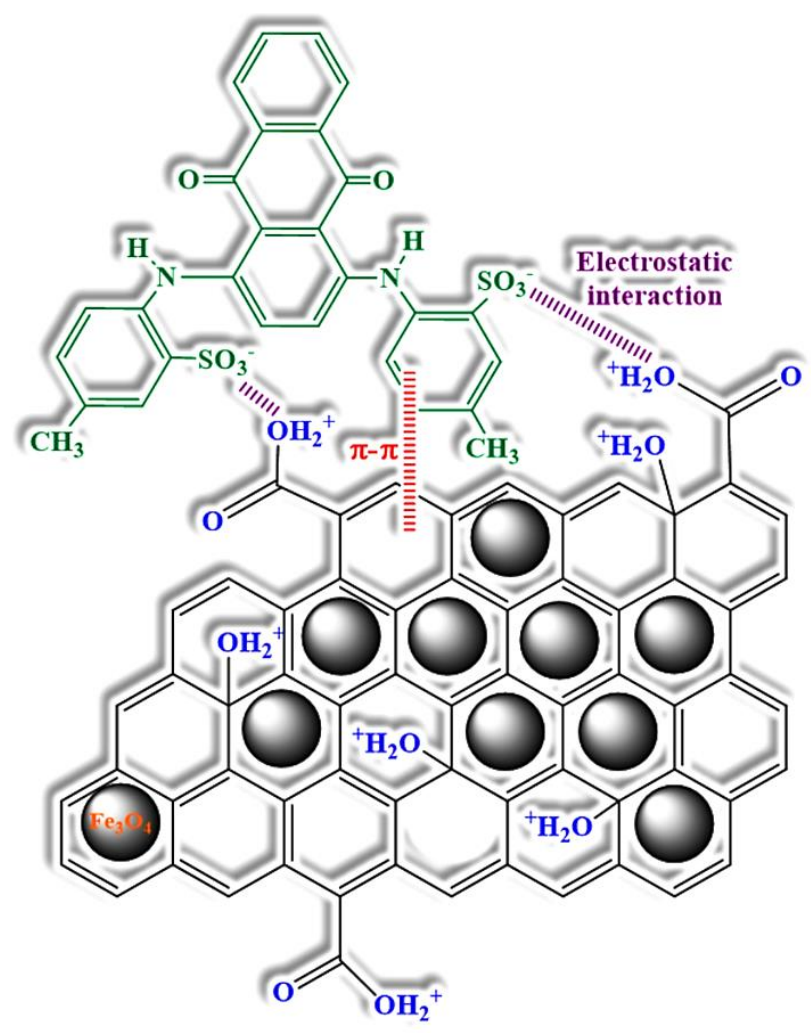

Figure 15. Adsorption mechanism of the AG-25 by Ch-rGO/Fe $\mathrm{O}_{4}$ nanostructure. 


\section{Degradation of AG-25 by Fenton reaction}

When the aqueous solutions of AG-25 were exposed to $\mathrm{H}_{2} \mathrm{O}_{2}$ in presence of the Ch-rGO/Fe $3 \mathrm{O}_{4}$ as a Fenton catalyst, the peroxide creates hydroxyl radicals on the surface of the catalysts for oxidation of the pollutant ${ }^{35,54}$. The effect of $\mathrm{H}_{2} \mathrm{O}_{2}$ concentration of the process efficiency was studied in concentration range of 0.01-0.1 M (2 mL of peroxide solution was used). Fig. 16a shows the kinetic curves of discoloration process, whereas Fig. 16b, the removal efficiency of the process at different $\mathrm{H}_{2} \mathrm{O}_{2}$ doses at $\mathrm{pH}=3$.
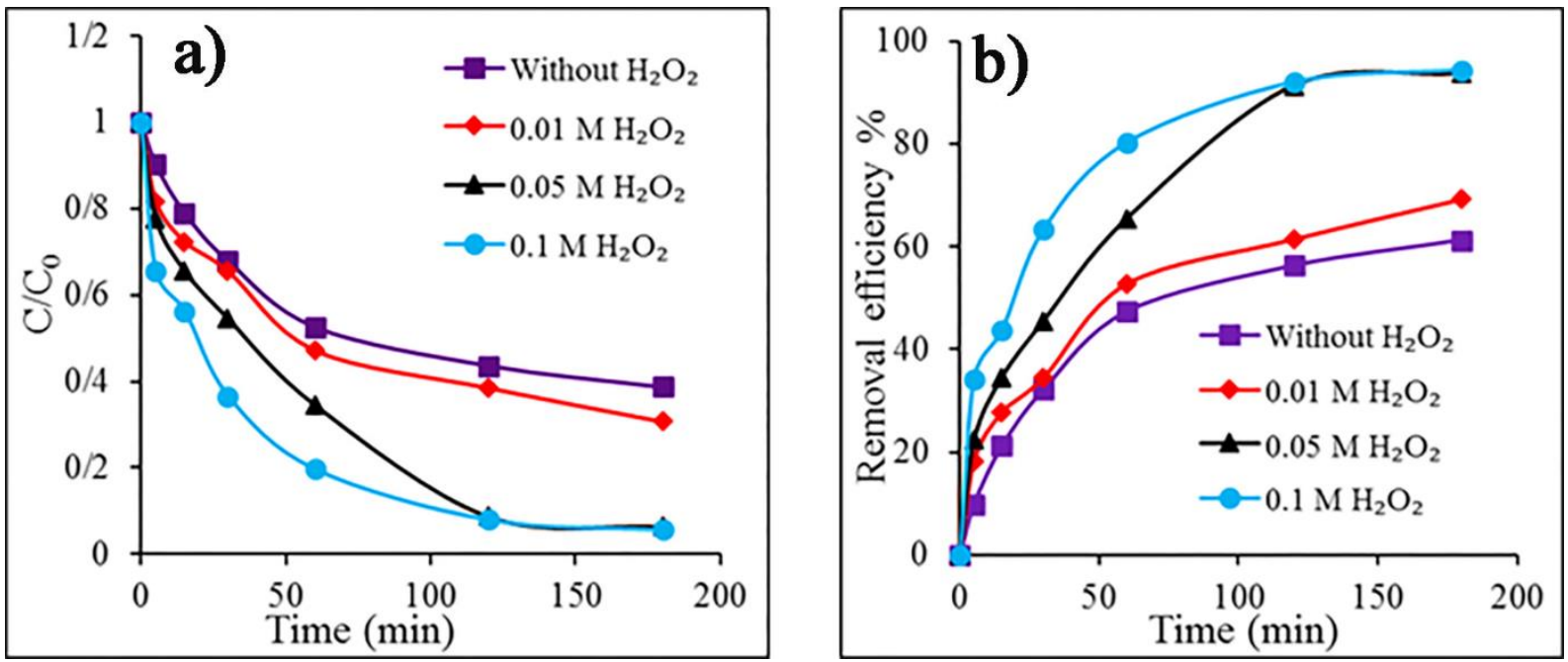

Figure 16. Effect of $\mathrm{H}_{2} \mathrm{O}_{2}$ dosage on the adsorption of $\mathrm{AG}-25$ by Ch-rGO/Fe ${ }_{3} \mathrm{O}_{4}$. Experimental conditions: dye concentration $0.5 \mathrm{mg} \cdot \mathrm{mL}^{-1}$, $\mathrm{RT}$, adsorbent dosage $0.010 \mathrm{~g}$, and $\mathrm{pH}=3$.

The discoloration experiments presented in Fig. 16 were performed in the most concentrated dye solution studied in this work $(0.5 \mathrm{M})$. Compared with the data in Fig. 16, where the maximum removal efficiency was slightly higher than $20 \%$ with the same amount of adsorbent $(0.010 \mathrm{~g})$, in presence of peroxide almost complete discoloration was achieved $(94 \%)$. The substantial enhancement of the removal efficiency is not a result only on the changed $\mathrm{pH}$ in this case $(\mathrm{pH}=3)$, but as well because, of the dye degradation occurred by the $\mathrm{OH}$ radicals. Fig. 16a shows that the rate of discoloration process increased with addition of peroxide and with 
increasing its concentration. Accordingly, the removal efficiency increased, too (Fig. 16b). This can be attributed to the increase in the amount of hydroxyl radicals produced. However, with further increase in hydrogen peroxide concentration from 0.05 to $0.1 \mathrm{M}$, the dye removal efficiency did not change. In excess quantity of $\mathrm{H}_{2} \mathrm{O}_{2}$, it acted as a scavenger of ${ }^{\circ} \mathrm{OH}$ via reacting with ${ }^{\circ} \mathrm{OH}$ to produce ${ }^{\circ} \mathrm{OOH} .^{55,56}$

The aqueous solution after $3 \mathrm{~h}$ of discoloration/degradation process was subjected to MALDITOF-MS analysis to check if the degradation of AG-25 proceeds and to identify the degradation products. This process was compared with the discoloration/degradation performed by neat 3DrGO nanostructure in presence of the peroxide at the same concentration $\left(0.1 \mathrm{M} \mathrm{H}_{2} \mathrm{O}_{2}\right)$. AG-25 original dye was analyzed by MALDI-TOF-MS, too. The mass spectra obtained are presented in Fig. 17. It is worth mentioning that the usefulness of MALDI-TOF-MS is especially useful for detection of degradation products of AG-25, due to the lack of fragmentation of the molecules during analysis.

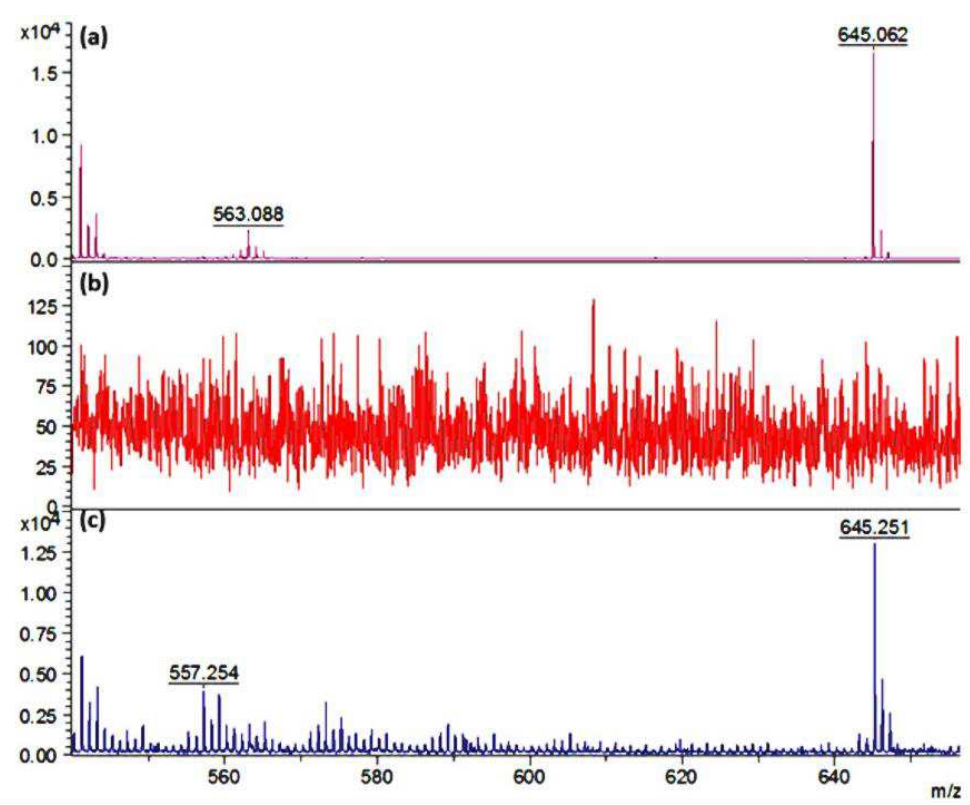

Figure 17. Comparison of average mass spectra of: (a) AG-25 (b) aqueous AG-25 solution after $3 \mathrm{~h}$ of Fenton's reaction over Ch-rGO/Fe $\mathrm{O}_{4}$ in presence of $0.1 \mathrm{M} \mathrm{H}_{2} \mathrm{O}_{2}$ (c) AG-25 after 3h with $\mathrm{H}_{2} \mathrm{O}_{2}(0.1$ M) and 3D-rGO (0.010 g). 
In Fig. 17a, where the mass spectrum of AG-25 dye is shown, the characteristic peak at $\mathrm{m} / \mathrm{z}$ 645 (AG-25 [M+Na] specie) can be observed. In Fig. 17c, where AG-25 aqueous solution after 3h discolouration by the neat 3D-rGO in presence of $\mathrm{H}_{2} \mathrm{O}_{2}$ is shown, this peak can be observed, too, indicating that $3 \mathrm{D}-\mathrm{rGO} / \mathrm{H}_{2} \mathrm{O}_{2}$ did not removed completely the dye from the solution. Moreover, in Fig. 17c, numerous new peaks aroused from the dye degradation appeared, pointing out that the dye was only partially degraded by the peroxide. On the other hand, the dye characteristic peak disappeared completely after Fenton's reaction performed over the Ch$\mathrm{rGO} / \mathrm{Fe}_{3} \mathrm{O}_{4}$ nanocatalyst and $\mathrm{H}_{2} \mathrm{O}_{2}$, demonstrating complete discoloration of the solution after $3 h$.
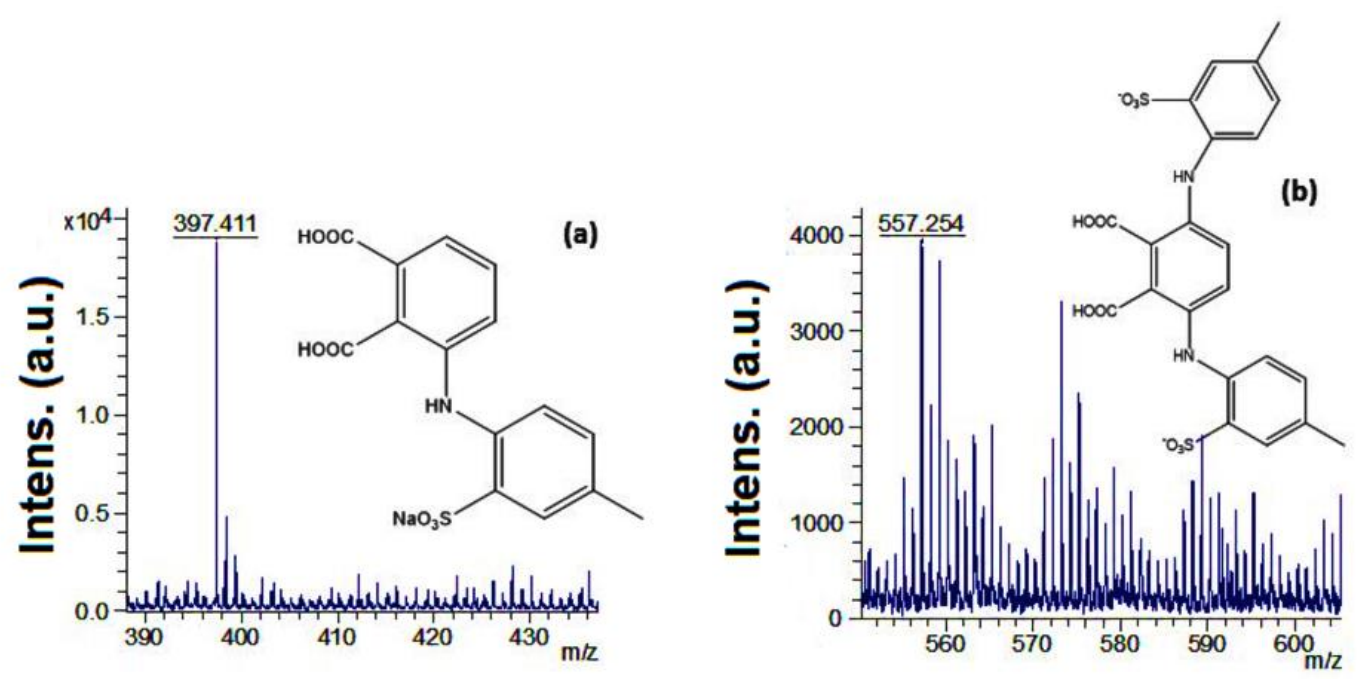

Figure 18. Mass spectra and the assignement of peaks observed in aqueous solution after dicoloration/degradation of AG-25 by $\mathrm{H}_{2} \mathrm{O}_{2}$ in presence of 3D-rGO.

The mass spectra of the aqueous solution treated with neat $3 \mathrm{D}-\mathrm{rGO} / \mathrm{H}_{2} \mathrm{O}_{2}$ was further analysed to check the type of the products formed. Fig. 18 presents the zoomed area of some characteristic peaks (molar mass of 397 and $557 \mathrm{~m} / \mathrm{z}$ ) and their assignments. Likely, the observed AG-25 degradation products contain multiple aromatic rings. These intermediate products behave as competitors to AG-25 for the adsorption sites, and react with the hydroxyl radicals, acting as hydroxyl radical scavengers, decreasing the removal efficiency. ${ }^{55,56}$ 

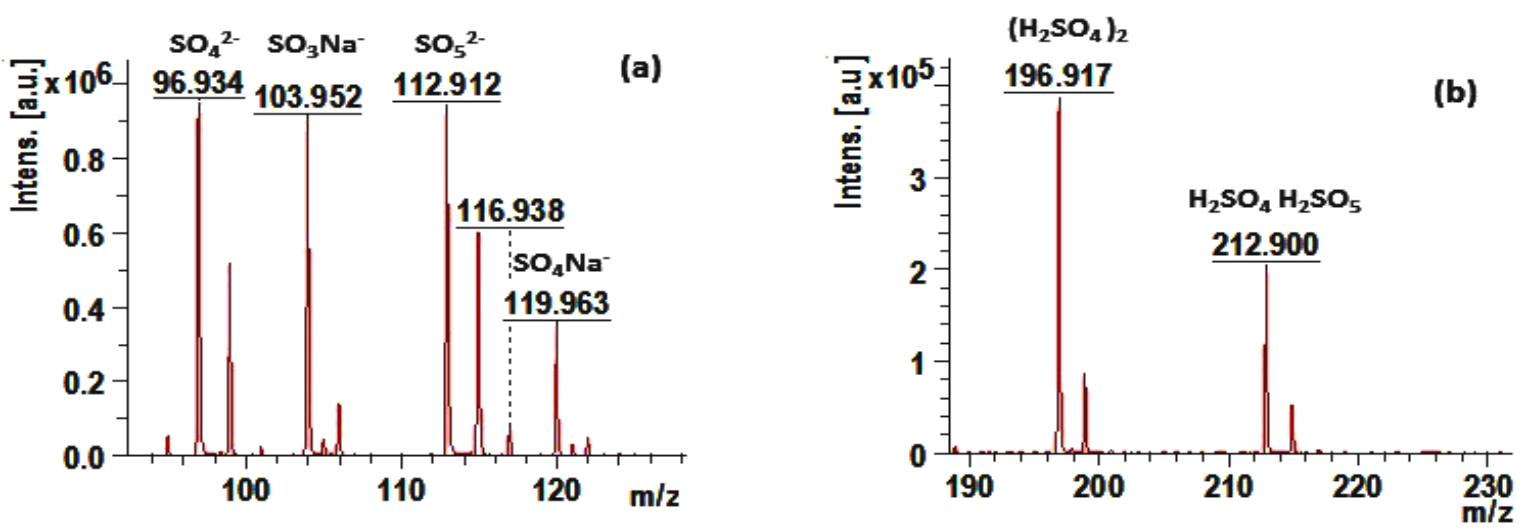

Figure 19. Zoomed areas of the MALDI-TOF-MS spectra of aqueous solution after $3 \mathrm{~h}$ discoloration/degradation of AG-25 dye solution at $\mathrm{pH}=3$, over $\mathrm{Ch}-\mathrm{rGO} / \mathrm{Fe}_{3} \mathrm{O}_{4}$ nanocatalysts $(0.010 \mathrm{~g})$ and $\mathrm{H}_{2} \mathrm{O}_{2}(0.1 \mathrm{M})$.

On the other hand, AG-25 was degraded completely by the Ch-rGO/Fe $3 \mathrm{O}_{4}-\mathrm{H}_{2} \mathrm{O}_{2}$. To check the type of the degradation products, in Fig. 19, the zoomed area of the peaks that appeared in Fig. 19b are shown. The observed products are $\mathrm{NaSO}_{3}{ }^{-}, \mathrm{SO}_{4}{ }^{2-}, \mathrm{SO}_{5}{ }^{2-}, \mathrm{NaSO}_{4}{ }^{-}$(Fig. 19a). In addition, sulphuric acid clusters were identified, which could be formed from degradation products interactions (Fig. 19b). No any larger organic degradation product with aromatic rings or conjugated aromatic rings were detected after Fenton's reaction, suggesting not only a full AG-25 degradation, but as well degradation of all intermediate products. With other words, Ch-rGO/ $\mathrm{Fe}_{3} \mathrm{O}_{4}$ ensures complete mineralization of $\mathrm{AG}-25$ in less than $30 \mathrm{~min}$ in as concentrated aqueous solution as $0.5 \mathrm{M}$, with only $0.010 \mathrm{~g}$ composite Fenton catalyst and in presence of $0.1 \mathrm{M} \mathrm{H}_{2} \mathrm{O}_{2}$. Moreover, this process was performed at room temperature without any additional energy source.

In the previous study, the excellent Fenton catalyst activity of the composite based on rGO and $\mathrm{Fe}_{3} \mathrm{O}_{4}$ nanoparticles was explained on the base of charge transfer complex established between both components, which facilitate the electron transfer and regeneration of ferrous ions after 'OH creation. ${ }^{35}$ The maximum efficiency was achieved for $0.12 \mathrm{mg} \cdot \mathrm{mL}^{-1}$ concentration of acid red dye, ensuring complete discoloration and partial degradation. In this study, the catalytic 
activity was further enhanced by the promotion of interactions between the $3 \mathrm{D}$ aerogel structure and the organic dye that allowed efficient discoloration and complete mineralization of $0.5 \mathrm{M}$ AG-25 dye solution, even in more concentrated dye solution and more chemically complex dye. The proposed AG-25 degradation mechanism, based on $\mathrm{rGO}-\mathrm{Fe}_{3} \mathrm{O}_{4}$ charge transfer complex is shown in Fig. 20. The efficiency of the charge transfer was improved due to the presence of the C-O-Fe bond, the formation of which is promoted by the production method of the in situ creation of the $\mathrm{Fe}_{3} \mathrm{O}_{4} \mathrm{NP}$.

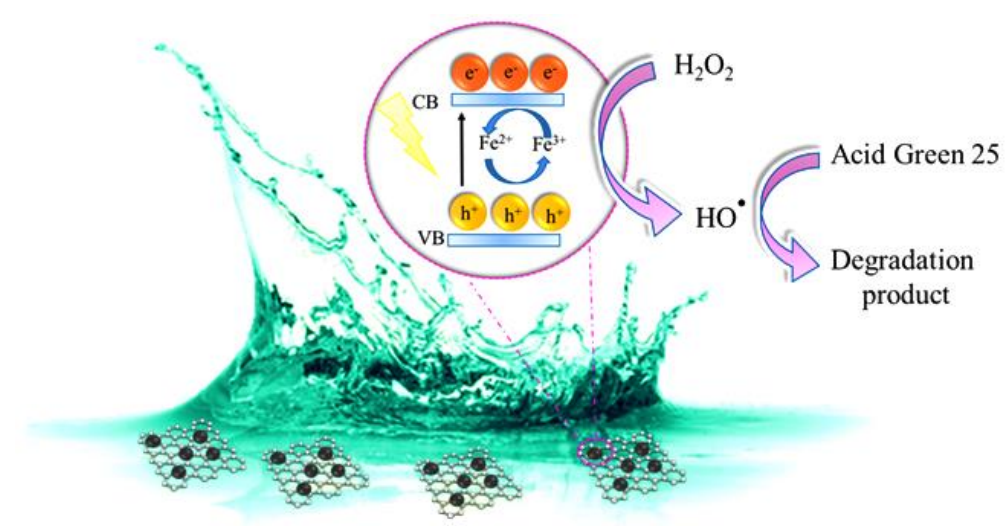

Figure 20. Proposed mechanism of AG-25 degradation in the $3 \mathrm{D} \mathrm{rGO} / \mathrm{Fe}_{3} \mathrm{O}_{4} / \mathrm{H}_{2} \mathrm{O}_{2}$ system.

\section{Conclusions}

In this study, 3D composite structures made of rGO and magnetic nanoparticles $\mathrm{Fe}_{3} \mathrm{O}_{4}$ were synthesized by self-assembly process, during simultaneous reduction of GO nanoplatelets and precursor for magnetic nanoparticles. The resulting 3D materials presented porous structure and high surface area, which were affected by the synthesis conditions and the reduction process type (either thermal or combined chemical and thermal reduction process).

Selected nanocomposite was applied as adsorbent of azo dye AG-25 from model aqueous solution, and the adsorption process was optimized by means of selection of quantity of 
adsorbent and $\mathrm{pH}$ of the dye aqueous solution. It was shown that, when $\mathrm{pH}$ is in-between the $\mathrm{pKa}$ of carboxylic groups on graphene and $\mathrm{pKa}$ of sulfonic acid group in AG-25, the removal efficiency is maximized. In such conditions ion-dipole interactions are promoted. The proposed adsorption mechanism is based on the mentioned electrostatic interactions and the possibility of $\pi-\pi$ bonding between the neat graphenic areas in rGO and the conjugated aromatic structure of AG-25.

In the next step, the $3 \mathrm{D}$ composite $\mathrm{rGO} / \mathrm{Fe}_{3} \mathrm{O}_{4}$ was applied as Fenton catalyst in presence of $\mathrm{H}_{2} \mathrm{O}_{2}$ for the AG-25 degradation and the performance was compared with the degradation of the dye by $\mathrm{H}_{2} \mathrm{O}_{2}$ in presence of neat 3D-rGO structure. By MALDI-TOF-MS analysis, it was determined that complete mineralization of AG-25 and all the intermediate products was attained by the Fenton reaction by $\mathrm{rGO} / \mathrm{Fe}_{3} \mathrm{O}_{4} / \mathrm{H}_{2} \mathrm{O}_{2}$ in as concentrated $\mathrm{AG}-25$ solution as 0.5 $\mathrm{mg} \cdot \mathrm{mL}^{-1}$, whereas only partial discoloration and presence of multiple reaction intermediates were observed in the solution after $\mathrm{rGO} / \mathrm{H}_{2} \mathrm{O}_{2}$ reaction. The complete degradation was achieved in less than $30 \mathrm{~min}$, at room temperature, without any external energy added in the system. The excellent performance was assigned to the rGO-magnetic nanoparticles charge transfer complex, built up by the establishing of the $\mathrm{C}-\mathrm{O}-\mathrm{Fe}$ covalent bond, promoted further by the selection of optimal discoloration/degradation conditions.

\section{Acknowledgements}

The authors gratefully acknowledge the financial support of the Basque government (GV IT999-16 and GV IT1069-16). 


\section{References}

1 Wrolstad, R. E. Color and pigment analyses in fruit products. (1993).

2 Maldonado-Larios, L. et al. Electrochemically-assisted fabrication of titaniumdioxide/polyaniline nanocomposite films for the electroremediation of congo red in aqueous effluents. Synth. Met. 268, 116464 (2020).

3 Song, W. et al. Adsorption-desorption behavior of magnetic amine $/ \mathrm{Fe}_{3} \mathrm{O}_{4}$ functionalized biopolymer resin towards anionic dyes from wastewater. Bioresour. Technol. 210, 123-130 (2016).

4 Mukherjee, A., Adak, M. K., Dhak, P. \& Dhak, D. A simple chemical method for the synthesis of $\mathrm{Cu}^{2+}$ engrafted $\mathrm{MgAl}_{2} \mathrm{O}_{4}$ nanoparticles: Efficient fluoride adsorbents, photocatalyst and latent fingerprint detection. J. Environ. Sci. 88, 301-315 (2020).

5 Pathania, D., Sharma, S. \& Singh, P. Removal of methylene blue by adsorption onto activated carbon developed from Ficus carica bast. Arab. J. Chem. 10, S1445-S1451 (2017).

6 Gupta, V. K., Kumar, R., Nayak, A., Saleh, T. A. \& Barakat, M. Adsorptive removal of dyes from aqueous solution onto carbon nanotubes: a review. Adv. Colloid Interface Sci. 193, 24-34 (2013).

7 Peng, N. et al. Superabsorbent cellulose-clay nanocomposite hydrogels for highly efficient removal of dye in water. ACS Sustain. Chem. Eng. 4, 7217-7224 (2016).

8 Hsu, T.-C. Adsorption of an acid dye onto coal fly ash. Fuel 87, 3040-3045 (2008).

9 Murray, A. \& Örmeci, B. Competitive effects of humic acid and wastewater on adsorption of Methylene Blue dye by activated carbon and non-imprinted polymers. J. Environ. Sci. 66, 310317 (2018).

10 Tara, N., Siddiqui, S. I., Rathi, G., Chaudhry, S. A. \& Asiri, A. M. Nano-engineered Adsorbent for the removal of dyes from water: A review. Curr. Anal. Chem. 16, 14-40 (2020).

11 Homaeigohar, S. The nanosized dye adsorbents for water treatment. Nanomaterials 10, 295 (2020).

12 Zare, K. et al. A comparative study on the basis of adsorption capacity between CNTs and activated carbon as adsorbents for removal of noxious synthetic dyes: a review. $J$. Nanostructure. Chem. 5, 227-236 (2015).

13 Allen, M. J., Tung, V. C. \& Kaner, R. B. Honeycomb carbon: a review of graphene. Chem. Rev. 110, 132-145 (2010).

14 Chowdhury, S. \& Balasubramanian, R. Recent advances in the use of graphene-family nanoadsorbents for removal of toxic pollutants from wastewater. Adv. Colloid Interface Sci. 204, 35-56 (2014).

15 Lai, K. C., Lee, L. Y., Hiew, B. Y. Z., Thangalazhy-Gopakumar, S. \& Gan, S. Environmental application of three-dimensional graphene materials as adsorbents for dyes and heavy metals: Review on ice-templating method and adsorption mechanisms. J. Environ. Sci. 79, 174-199 (2019).

16 Mahmoudi, E. et al. Simultaneous removal of Congo red and cadmium (II) from aqueous solutions using graphene oxide-silica composite as a multifunctional adsorbent. J. Environ. Sci. 98, 151-160 (2020).

17 Kyzas, G. Z., Deliyanni, E. A., Bikiaris, D. N. \& Mitropoulos, A. C. Graphene composites as dye adsorbents. Chem. Eng. Res. Des. 129, 75-88 (2018).

18 Ramesha, G., Kumara, A. V., Muralidhara, H. \& Sampath, S. Graphene and graphene oxide as effective adsorbents toward anionic and cationic dyes. J. Colloid Interface Sci. 361, 270-277 (2011).

19 Robati, D. et al. Removal of hazardous dyes-BR 12 and methyl orange using graphene oxide as an adsorbent from aqueous phase. Chem. Eng. Technol. 284, 687-697 (2016).

20 Gulati, A. \& Kakkar, R. Graphene-based adsorbents for water remediation by removal of organic pollutants: Theoretical and experimental insights. Chem. Eng. Res. Des. 153, 21-36 (2020).

21 Su, S. et al. A novel graphene oxide-carbon nanotubes anchored $\alpha-\mathrm{FeOOH}$ hybrid activated persulfate system for enhanced degradation of Orange II. J. Environ. Sci. 83, 73-84 (2019). 
Hong, P. N., Minh, D. N., Van Hung, N., Minh, P. N. \& Khoi, P. H. Carbon nanotube and graphene aerogels-the world's 3D lightest materials for environment applications: A review. Int. J. Mater. Sci. Appl 6, 277-283 (2017).

23 Ye, S., Liu, Y. \& Feng, J. Low-density, mechanical compressible, water-induced selfrecoverable graphene aerogels for water treatment. ACS Appl. Mater. Interfaces. 9, 2245622464 (2017).

24 Dong, S. et al. Controlled synthesis of flexible graphene aerogels macroscopic monolith as versatile agents for wastewater treatment. Appl. Surf. Sci. 445, 30-38 (2018).

25 Jiang, L., Wen, Y., Zhu, Z., Liu, X. \& Shao, W. A Double cross-linked strategy to construct graphene aerogels with highly efficient methylene blue adsorption performance. Chemosphere 265, 129169 (2020).

26 Li, Z.-J. et al. Enhanced photocatalytic removal of uranium (VI) from aqueous solution by magnetic $\mathrm{TiO}_{2} / \mathrm{Fe}_{3} \mathrm{O}_{4}$ and its graphene composite. Environ. Sci. Technol. 51, 5666-5674 (2017).

Pourjavadi, A., Nazari, M. \& Hosseini, S. H. Synthesis of magnetic graphene oxide-containing nanocomposite hydrogels for adsorption of crystal violet from aqueous solution. RSC Adv. $\mathbf{5}$, 32263-32271 (2015).

$28 \mathrm{Li}$, S. et al. Highly efficient degradation of organic dyes by palladium nanoparticles decorated on 2D magnetic reduced graphene oxide nanosheets. Dalton Trans. 44, 9193-9199 (2015).

29 He, K. et al. Three-dimensional graphene supported catalysts for organic dyes degradation. Appl. Catal. B. 228, 19-28 (2018).

30 Shan, D. et al. Hydrophilic and strengthened 3D reduced graphene oxide/nano- $\mathrm{Fe}_{3} \mathrm{O}_{4}$ hybrid hydrogel for enhanced adsorption and catalytic oxidation of typical pharmaceuticals. Environ. Sci. Nano 5, 1650-1660 (2018).

31 Lu, J., Zhou, Y., Lei, J., Ao, Z. \& Zhou, Y. $\mathrm{Fe}_{3} \mathrm{O}_{4} /$ graphene aerogels: A stable and efficient persulfate activator for the rapid degradation of malachite green. Chemosphere 251, 126402 (2020).

32 Zhang, F., Xue, X., Huang, X. \& Yang, H. Adsorption and heterogeneous Fenton catalytic performance for magnetic $\mathrm{Fe}_{3} \mathrm{O}_{4} /$ reduced graphene oxide aerogel. J. Mater. Sci. 55, 15695 15708 (2020).

33 Duc, D. S., Hoan, N. X., Tho, N. H. \& Viet, N. X. Synthesis of $\mathrm{Fe}_{3} \mathrm{O}_{4}$-reduced graphene oxide modified tissue-paper and application in the treatment of methylene blue. VNU Journal of Science: Natural Sciences and Technology 35 (2019) 56-63. https://doi.org/10. 25073/25881140/vnunst.4883.

$34 \mathrm{Li}$, Y., Zhang, R., Tian, X., Yang, C. \& Zhou, Z. Facile synthesis of $\mathrm{Fe}_{3} \mathrm{O}_{4}$ nanoparticles decorated on 3D graphene aerogels as broad-spectrum sorbents for water treatment. Appl. Surf. Sci. 369, 11-18 (2016).

35 Sadegh, F. et al. A green synthesis of nanocatalysts based on reduced graphene oxide/magnetic nanoparticles for the degradation of Acid Red 1. RSC Adv. 10, 38805-38817 (2020).

36 Zhang, M.-h., Dong, H., Zhao, L., Wang, D.-x. \& Meng, D. A review on Fenton process for organic wastewater treatment based on optimization perspective. Sci. Total Environ. 670, 110121 (2019).

37 Rezaei, F. \& Vione, D. Effect of $\mathrm{pH}$ on zero valent iron performance in heterogeneous fenton and fenton-like processes: A review. Molecules 23, 3127 (2018).

38 Szpyrkowicz, L., Juzzolino, C. \& Kaul, S. N. A comparative study on oxidation of disperse dyes by electrochemical process, ozone, hypochlorite and Fenton reagent. Water Res. 35, 21292136 (2001).

39 Lu, H.-F., Chen, H.-F., Kao, C.-L., Chao, I. \& Chen, H.-Y. A computational study of the Fenton reaction in different $\mathrm{pH}$ ranges. Phys. Chem. Chem. 20, 22890-22901 (2018).

40 Barrera-Díaz, C., Canizares, P., Fernández, F., Natividad, R. \& Rodrigo, M. A.

Electrochemical advanced oxidation processes: an overview of the current applications to actual industrial effluents. J. Mex. Chem. 58, 256-275 (2014).

41 Jung, Y. S., Lim, W. T., Park, J. Y. \& Kim, Y. H. Effect of pH on Fenton and Fenton-like oxidation. Environ. Technol. 30, 183-190 (2009).

42 Vasquez-Medrano, R., Prato-Garcia, D. \& Vedrenne, M. in Advanced Oxidation Processes for Waste Water Treatment 89-113 (Elsevier, 2018). 
Thomas, N., Dionysiou, D. D. \& Pillai, S. C. Heterogeneous Fenton catalysts: A review of $\begin{array}{lllll}\text { recent advances. } & \text { J. Hazard. }\end{array}$ https://doi.org/10.1016/j.jhazmat.2020.124082 (2020).

44 Nworie, F., Nwabue, F., Oti, W., Mbam, E. \& Nwali, B. Removal of methylene blue from aqueous solution using activated rice husk biochar: adsorption isotherms, kinetics and error analysis. J. Chil. Chem. Soc. 64, 4365-4376 (2019).

45 Politakos, N. et al. Graphene-based monolithic nanostructures for $\mathrm{CO}_{2}$ capture. Ind. Eng. Chem. Res. 59, 8612-8621 (2020).

46 Cychosz, K. A. \& Thommes, M. Progress in the physisorption characterization of nanoporous gas storage materials. engr. 4, 559-566 (2018).

47 Grosman, A. \& Ortega, C. Nature of capillary condensation and evaporation processes in ordered porous materials. Langmuir 21, 10515-10521 (2005).

48 Zubir, N. A., Yacou, C., Motuzas, J., Zhang, X. \& Da Costa, J. C. D. Structural and functional investigation of graphene oxide- $\mathrm{Fe}_{3} \mathrm{O}_{4}$ nanocomposites for the heterogeneous Fenton-like reaction. Sci. Rep. 4, 1-8 (2014).

49 Kumar, R., Singh, R. K., Vaz, A. R., Savu, R. \& Moshkalev, S. A. Self-assembled and one-step synthesis of interconnected 3D network of $\mathrm{Fe}_{3} \mathrm{O}_{4} /$ reduced graphene oxide nanosheets hybrid for high-performance supercapacitor electrode. ACS Appl. Mater. Interfaces 9, 8880-8890 (2017).

50 Cheng, G. et al. The $\mathrm{GO} / \mathrm{rGO}-\mathrm{Fe}_{3} \mathrm{O}_{4}$ composites with good water-dispersibility and fast magnetic response for effective immobilization and enrichment of biomolecules. J. Mater. Chem. 22, 21998-22004 (2012).

51 Liu, L. et al. An electrochemical sensor for diphenylamine detection based on reduced graphene oxide/ $\mathrm{Fe}_{3} \mathrm{O}_{4}$-molecularly imprinted polymer with 1, 4-Butanediyl-3, 3'-bis-1-vinylimidazolium dihexafluorophosphate ionic liquid as cross-linker. Polymers 10, 1329 (2018).

52 Namazian, M. \& Halvani, S. Calculations of pKa values of carboxylic acids in aqueous solution using density functional theory. J. Chem. Thermodyn. 38, 1495-1502 (2006).

53 Rayne, S., Forest, K. \& Friesen, K. Extending the semi-empirical PM6 method for carbon oxyacid pKa prediction to sulfonic acids: Application towards congener-specific estimates for the environmentally and toxicologically relevant $\mathrm{C} 1$ through $\mathrm{C} 8$ perfluoroalkyl derivatives. Nat. Preced. (2009).

54 Qiu, B., Li, Q., Shen, B., Xing, M. \& Zhang, J. Stöber-like method to synthesize ultradispersed $\mathrm{Fe}_{3} \mathrm{O}_{4}$ nanoparticles on graphene with excellent Photo-Fenton reaction and high-performance lithium storage. Appl. Catal. B-Environ 183, 216-223 (2016).

55 Yang, X. et al. Rapid degradation of methylene blue in a novel heterogeneous $\mathrm{Fe}_{3} \mathrm{O}_{4} @ \mathrm{rGO} @$ $\mathrm{TiO}_{2}$-catalyzed photo-Fenton system. Sci. Rep. 5, 10632 (2015).

56 Qin, Y., Long, M., Tan, B. \& Zhou, B. RhB adsorption performance of magnetic adsorbent $\mathrm{Fe}_{3} \mathrm{O}_{4} / \mathrm{RGO}$ composite and its regeneration through a fenton-like reaction. Nano-Micro. Lett. 6 , 125-135 (2014). 
Figures

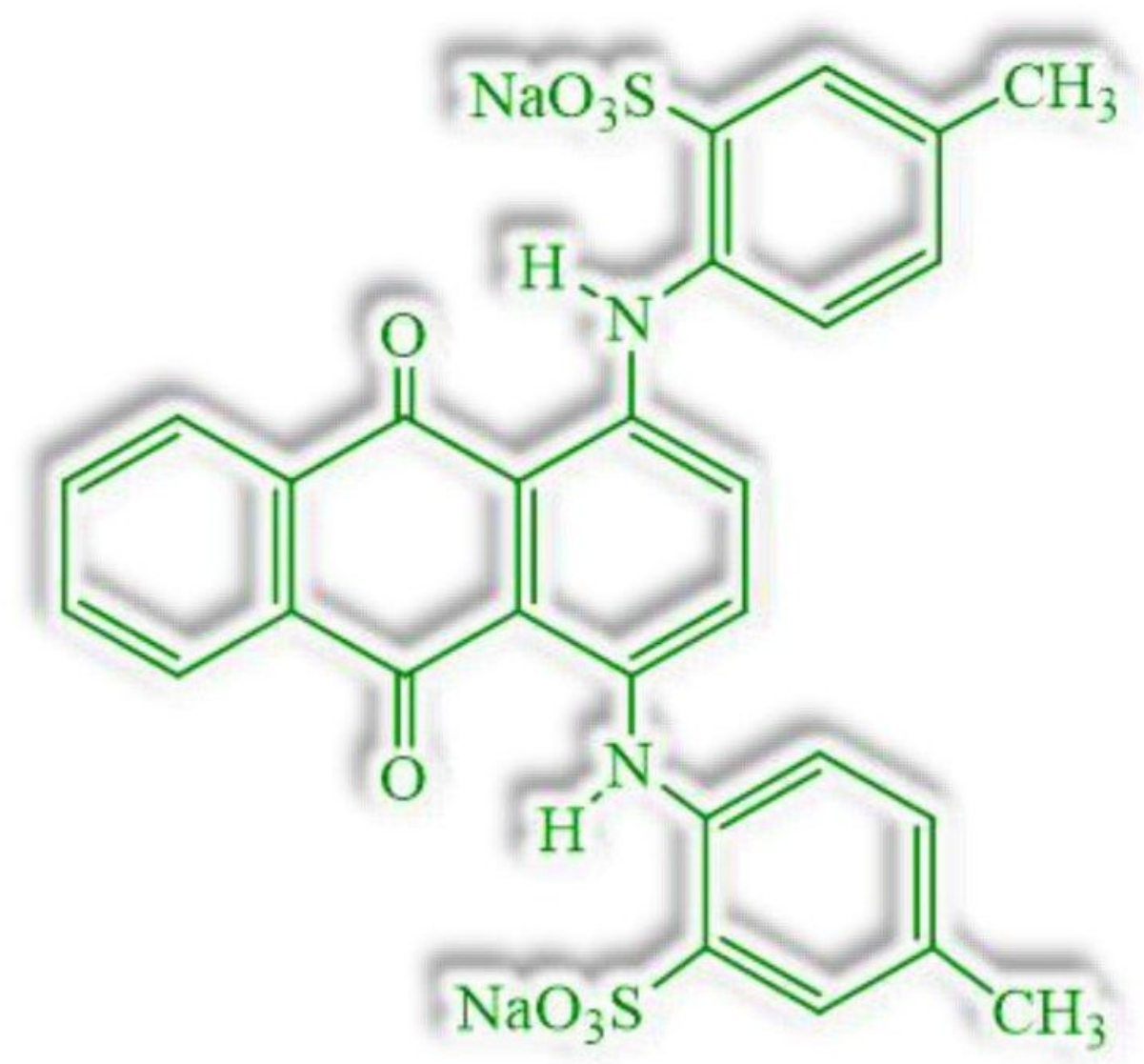

Figure 1

Chemical structure of AG-25 dye. 


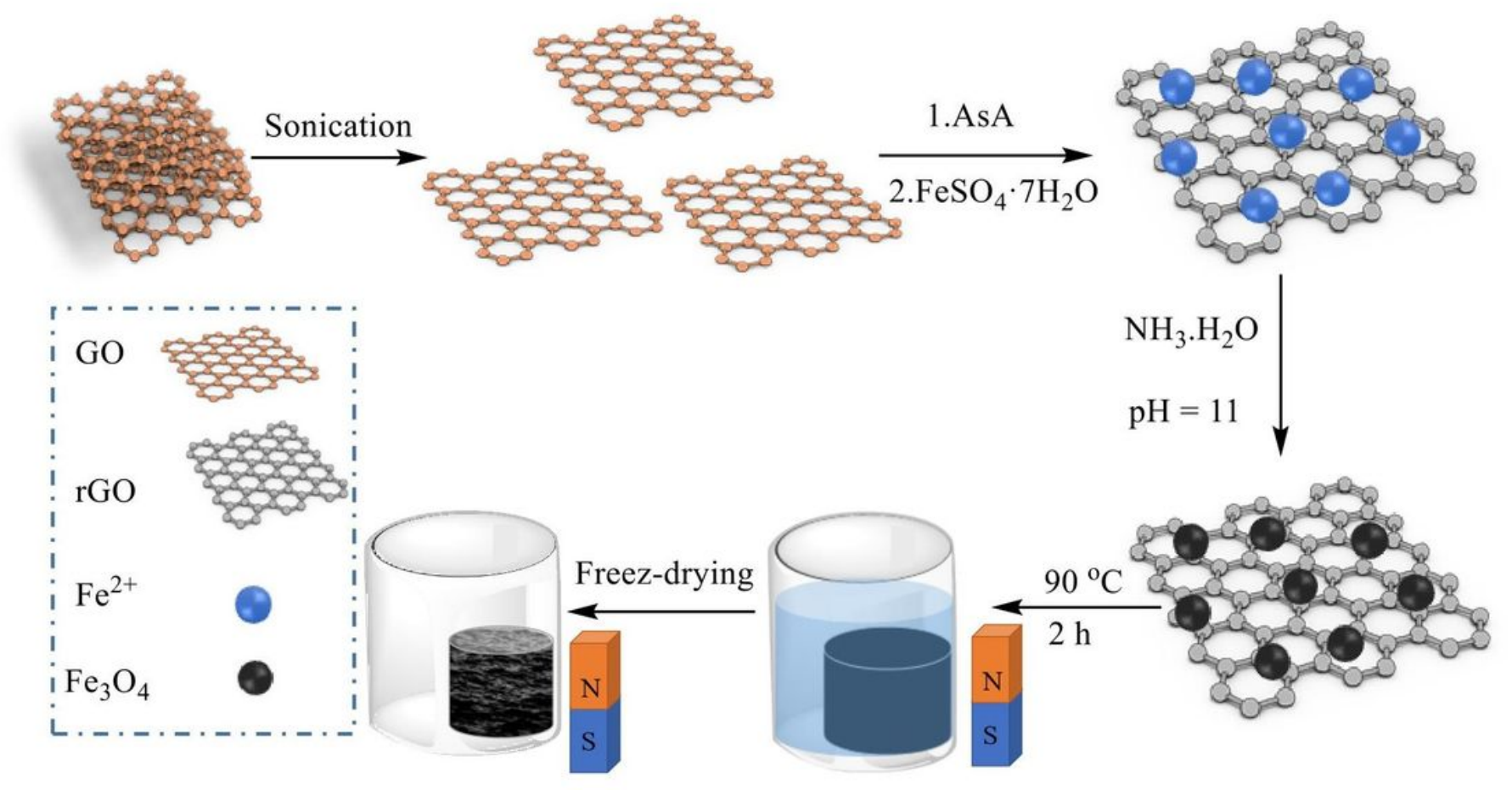

Figure 2

Schematic diagram of the preparation of the 3D-rGO/Fe304 nanostructures. 
a)

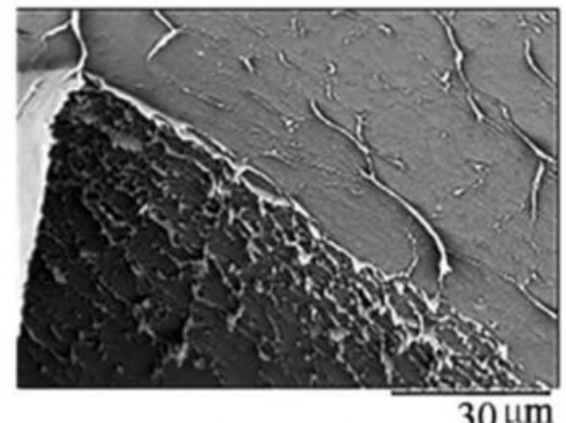

b)

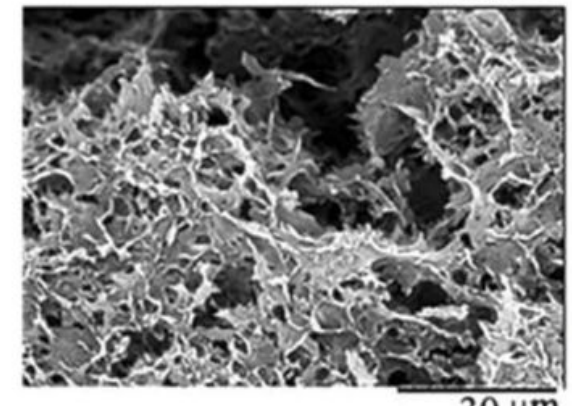

c)

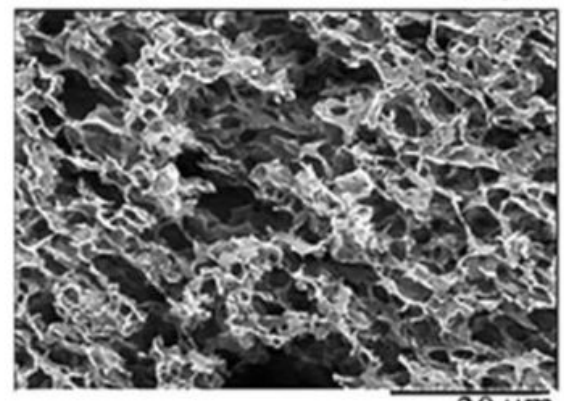

d)

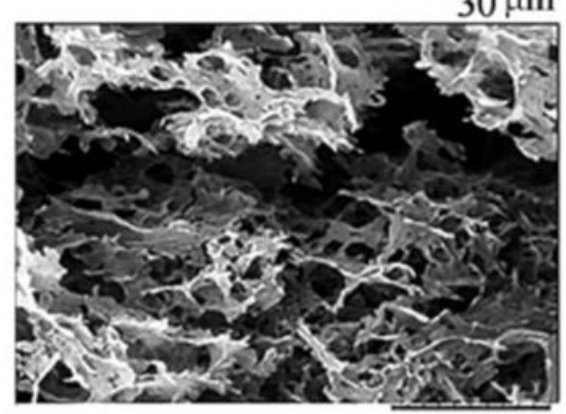

$30 \mu \mathrm{m}$
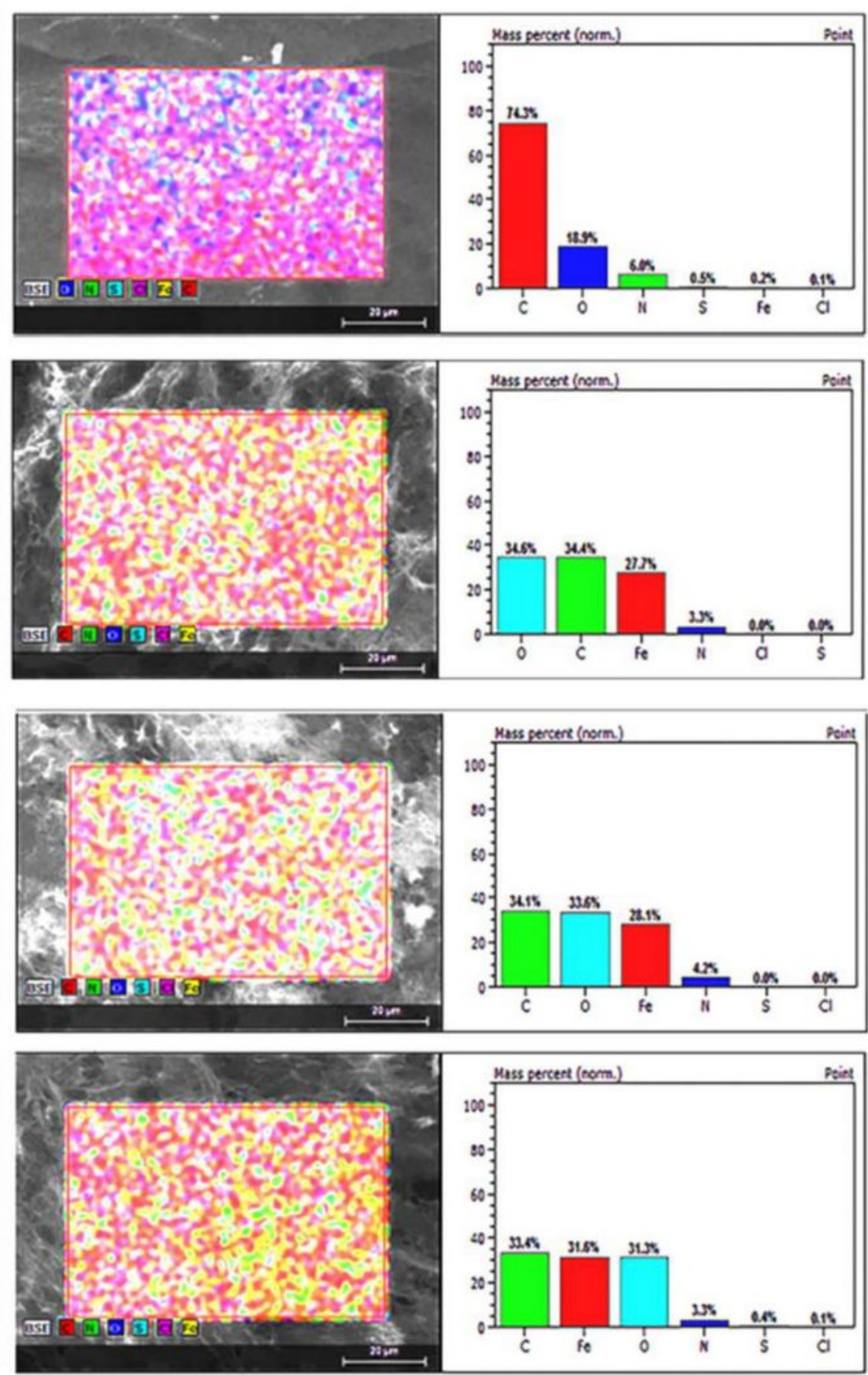

Figure 3

Surface morphology, mapping and elemental composition of the 3D nanocomosites (a) Neat 3D-rGO; (b) Th-rGO/Fe304/PVP; (c) Ch-rGO/Fe304; and (d) Th-rGO/Fe304. 



Figure 4

SEM micrographs of Ch-rGO/Fe304 nanostructure obtained by heat-drying under lower (left) and higher (right) magnification. The inset in the right image show a photo of flower with similar structuring.

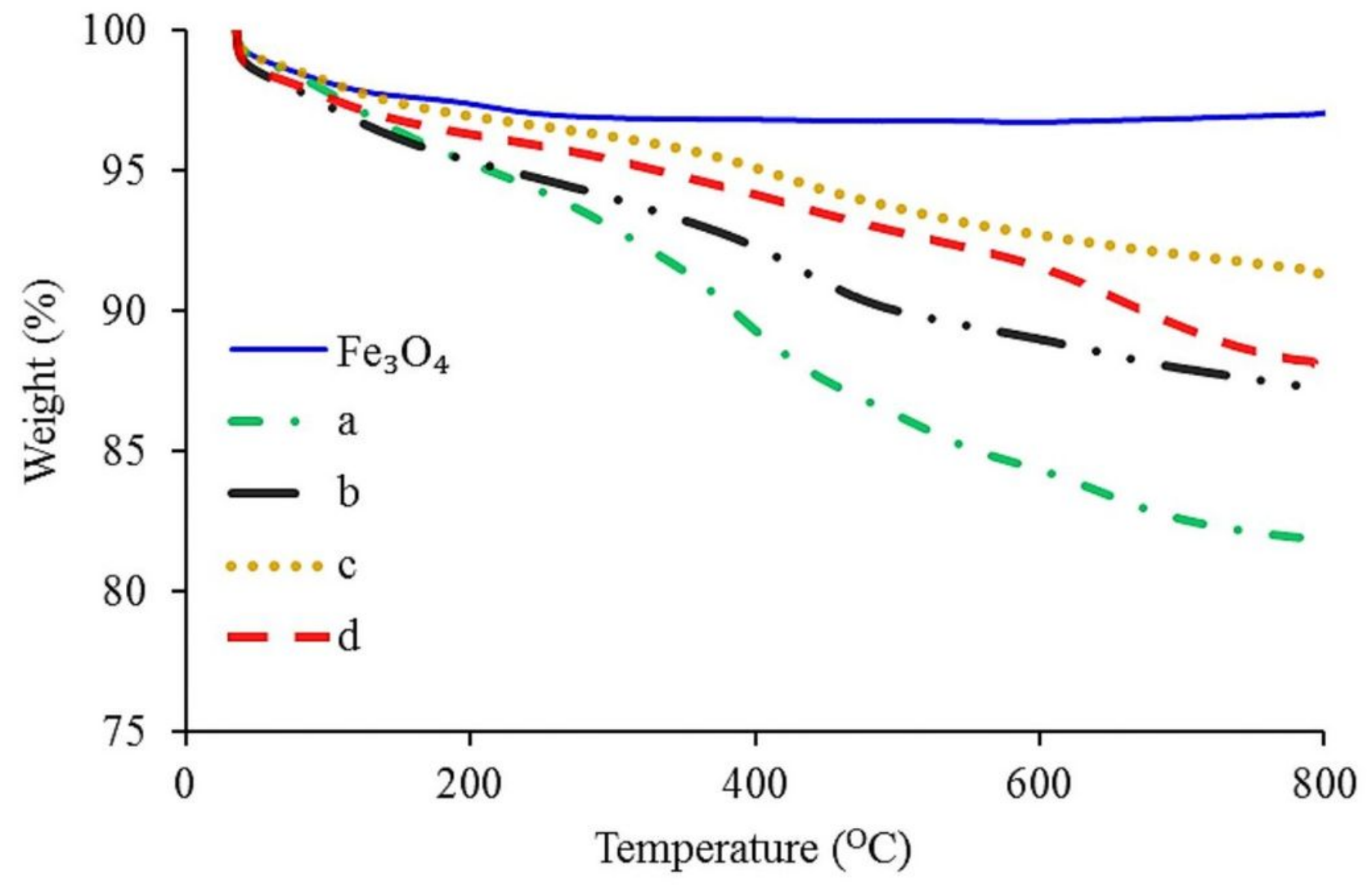

Figure 5 
TGA results of neat Fe304 nanoparticles; (a) neat3D-rGO; (b) Th-rGO/Fe304/PVP; (c) Ch-rGO/Fe304; and (d) Th-rGO/Fe304.

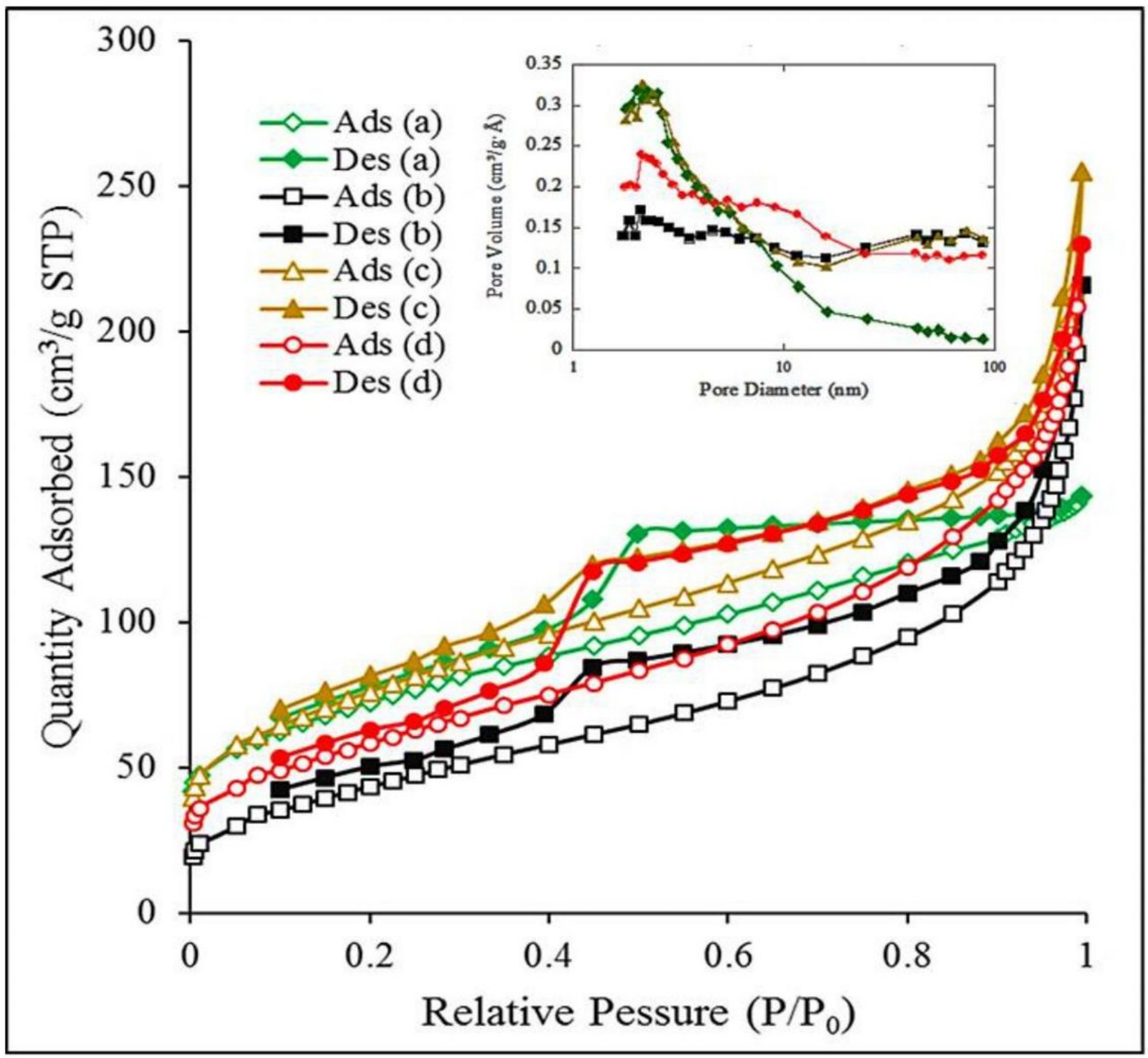

Figure 6

Adsorption-desorption isotherm of N2 (inset shows pore size distribution) of (a) neat 3D- rGO; (b) ThrGO/Fe304/PVP; (c) Ch-rGO/Fe304; and (d) Th-rGO/Fe304. In the inset, pore size distributions of the same materials are presented. 

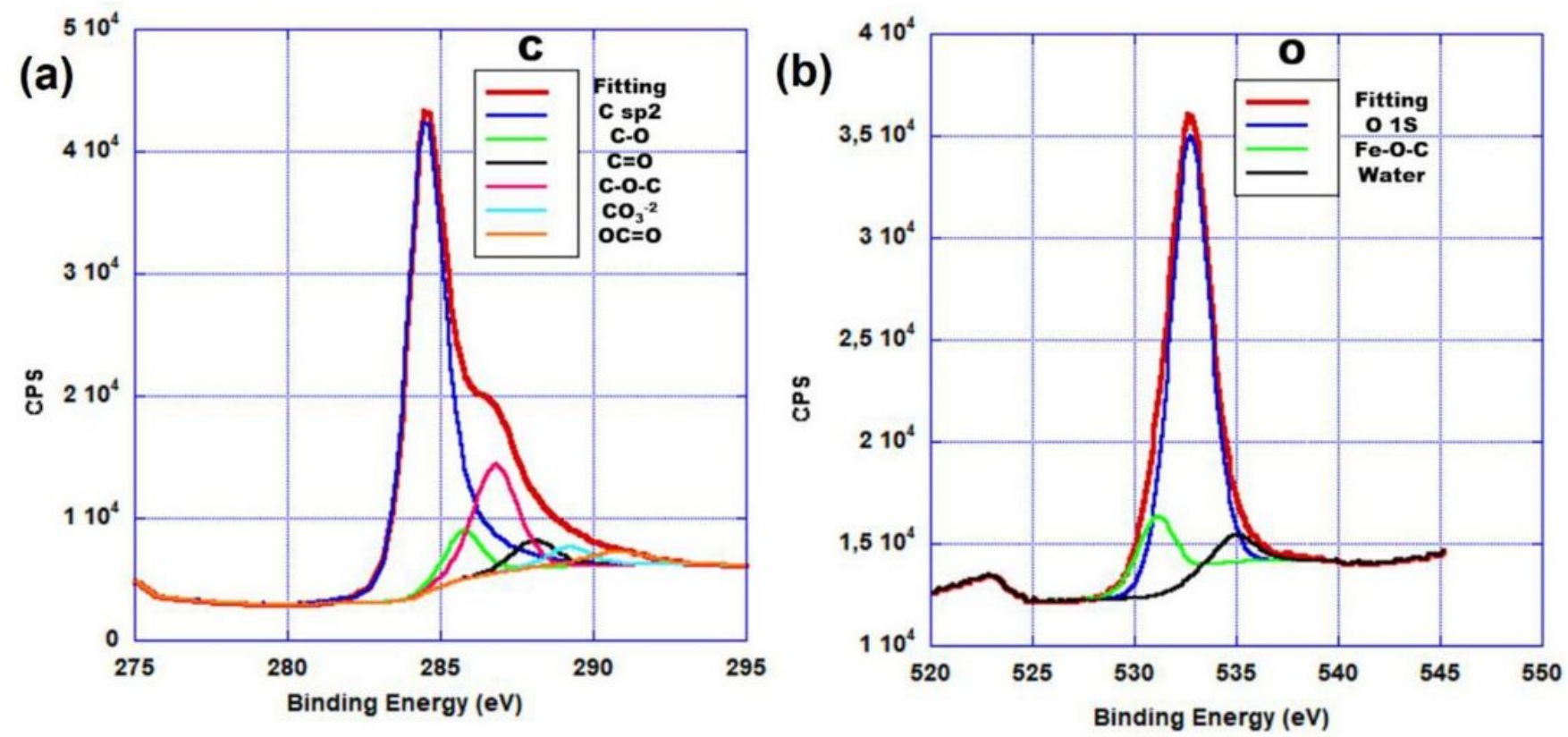

Figure 7

XPS spectra of Ch-rGO/Fe304 (a) C 1s and (b) 0 1s core level spectra.

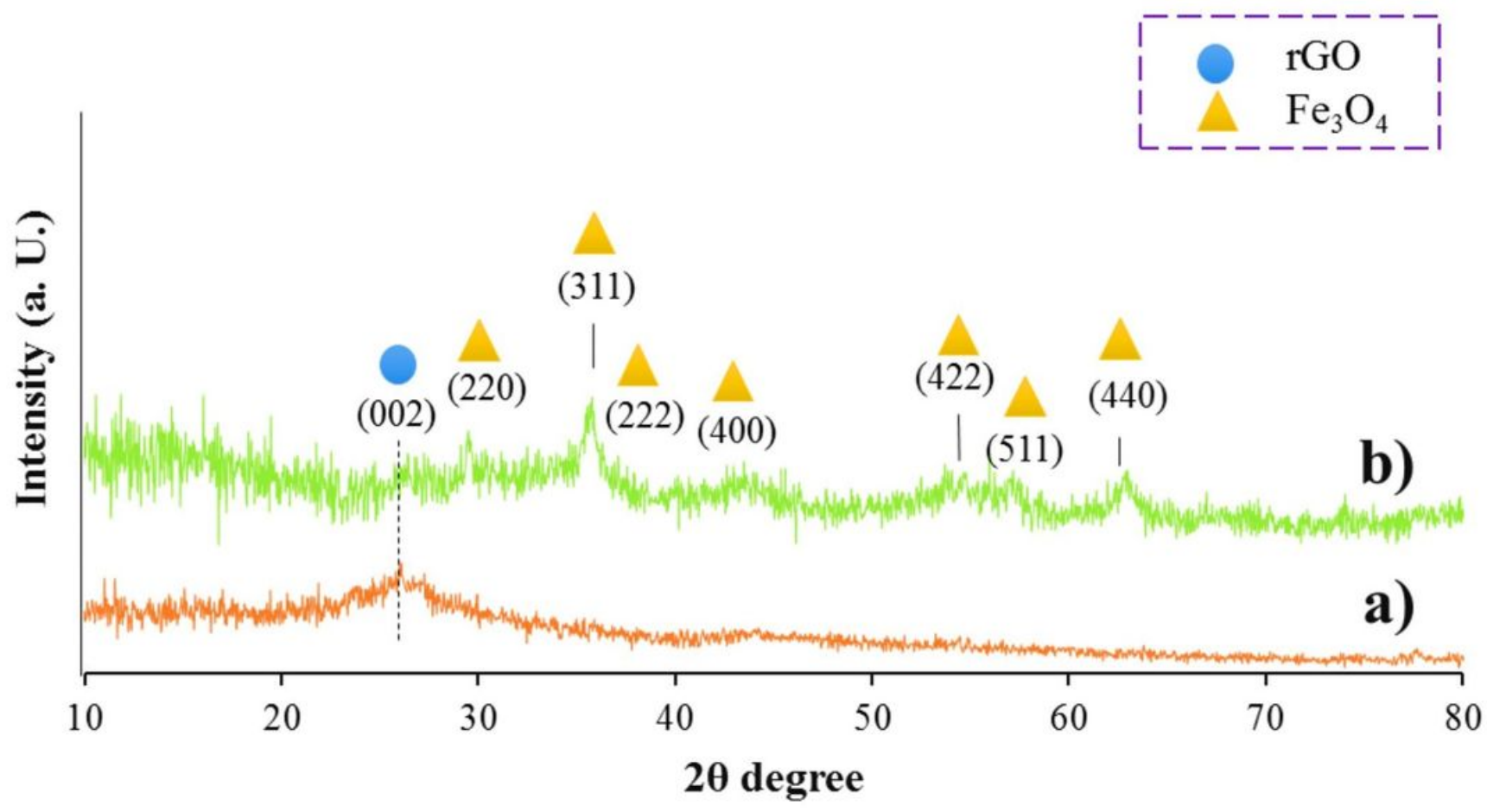

Figure 8

XRD patterns of (a) neat rGO and (b) Ch-rGO/Fe3O4. 


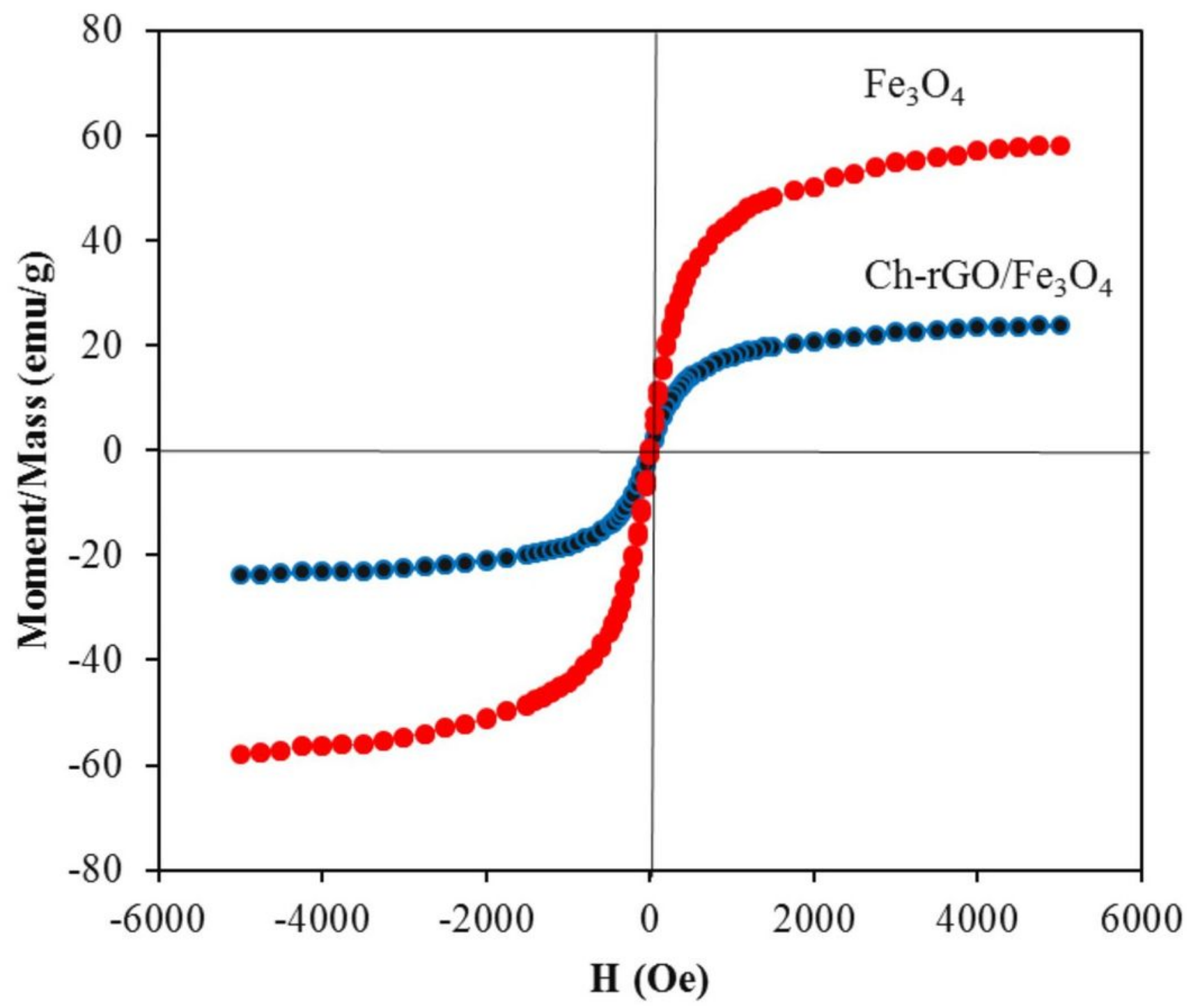

Figure 9

Magnetization curves of $\mathrm{Fe} 3 \mathrm{O} 4$ and $\mathrm{Ch}-\mathrm{RGO} / \mathrm{Fe} 3 \mathrm{O} 4$ at room temperature.

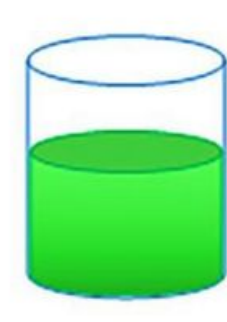

Dye Solution

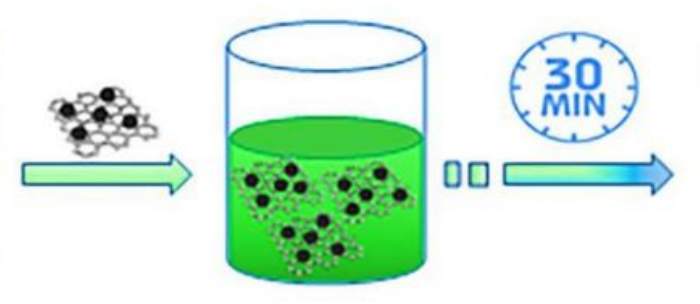

Adsorption Process
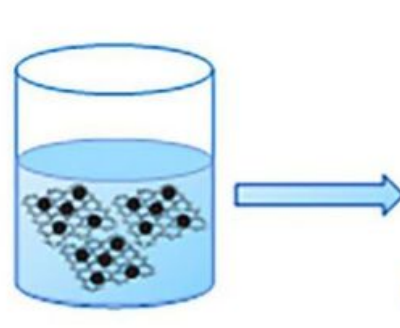

After Adsorption

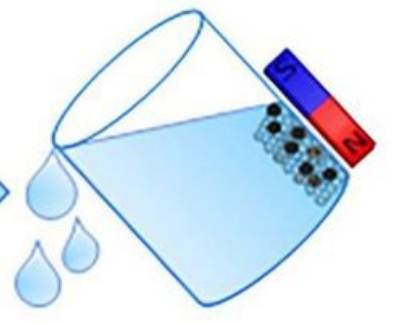

Removal of Adsorbent

Figure 10

Schematic illustration of the adsorption process for the AG-25 using Ch-rGO/Fe304. 




Figure 11

Effect of adsorbent kind on adsorption of AG-25 by neat rGO and Ch-rGO/Fe304. Experimental conditions: adsorbent dosage $0.010 \mathrm{~g}$, dye concentration $0.01 \mathrm{mg} \cdot \mathrm{mL}-1, \mathrm{RT}$, and natural $\mathrm{pH}$; Inset: Photos of the discoloration process and separation of the nanostructure afterward. 

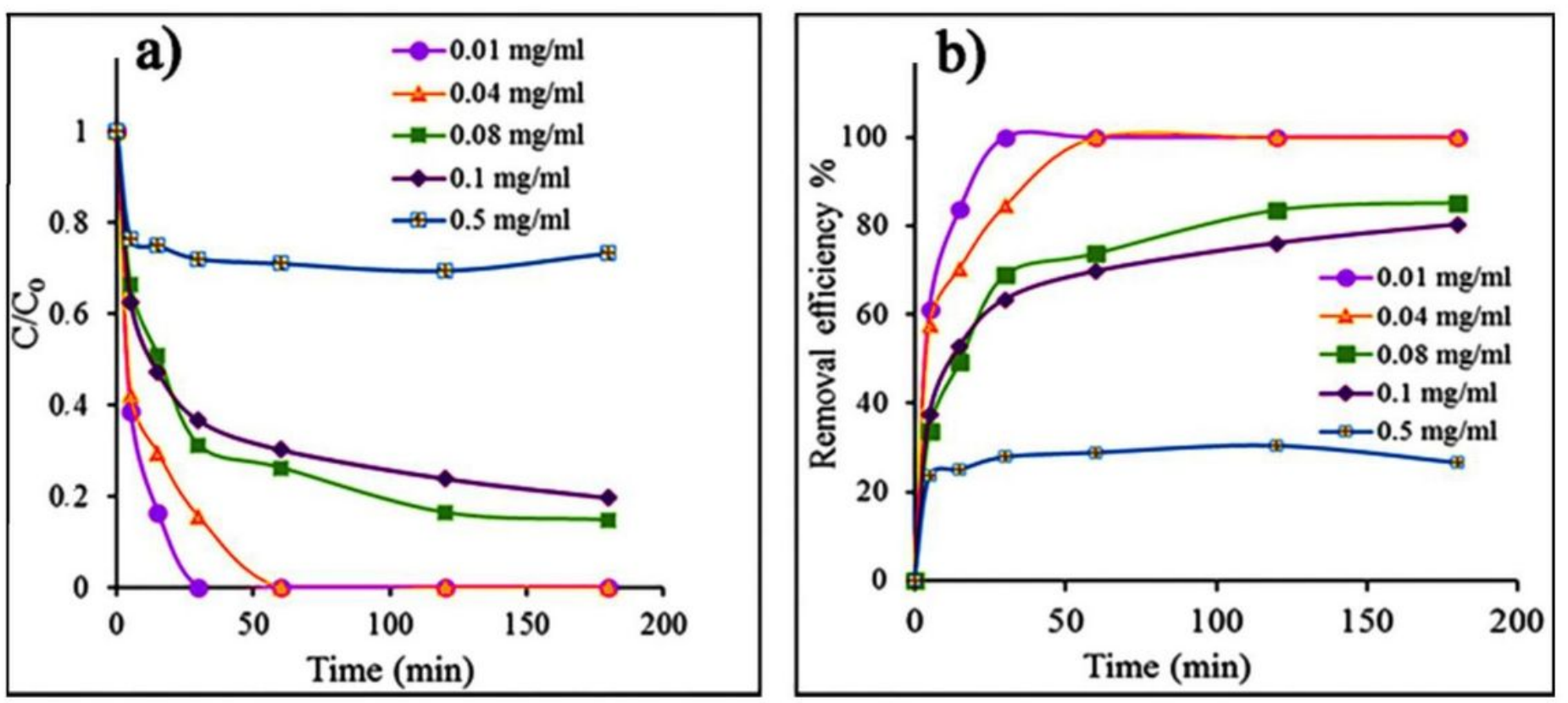

Figure 12

Effect of initial dye concentration on adsorption of AG-25 by Ch-rGO/Fe304. Experimental conditions: adsorbent dose $0.010 \mathrm{~g}, \mathrm{RT}$, and natural $\mathrm{pH}$.
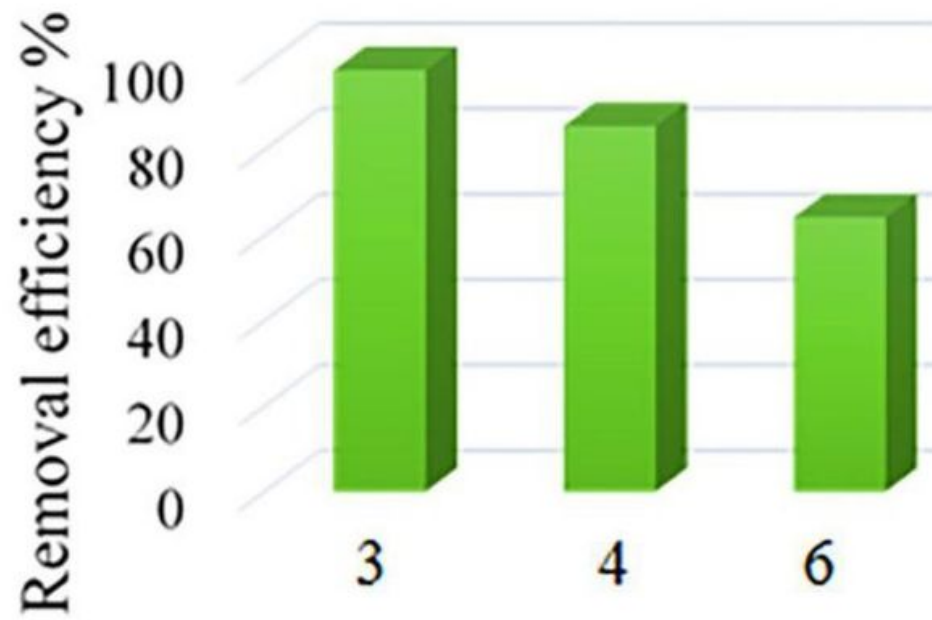

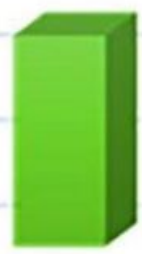

8 10

$\mathrm{pH}$

Figure 13

Effect of $\mathrm{pH}$ on the adsorption of $\mathrm{AG}-25$ by $\mathrm{Ch}-\mathrm{rGO} / \mathrm{Fe} 304$. Experimental conditions: adsorbent contact time $180 \mathrm{~min}$, dye concentration $0.1 \mathrm{mg} \cdot \mathrm{mL}-1, \mathrm{RT}$, and adsorbent dose $0.010 \mathrm{~g}$. 

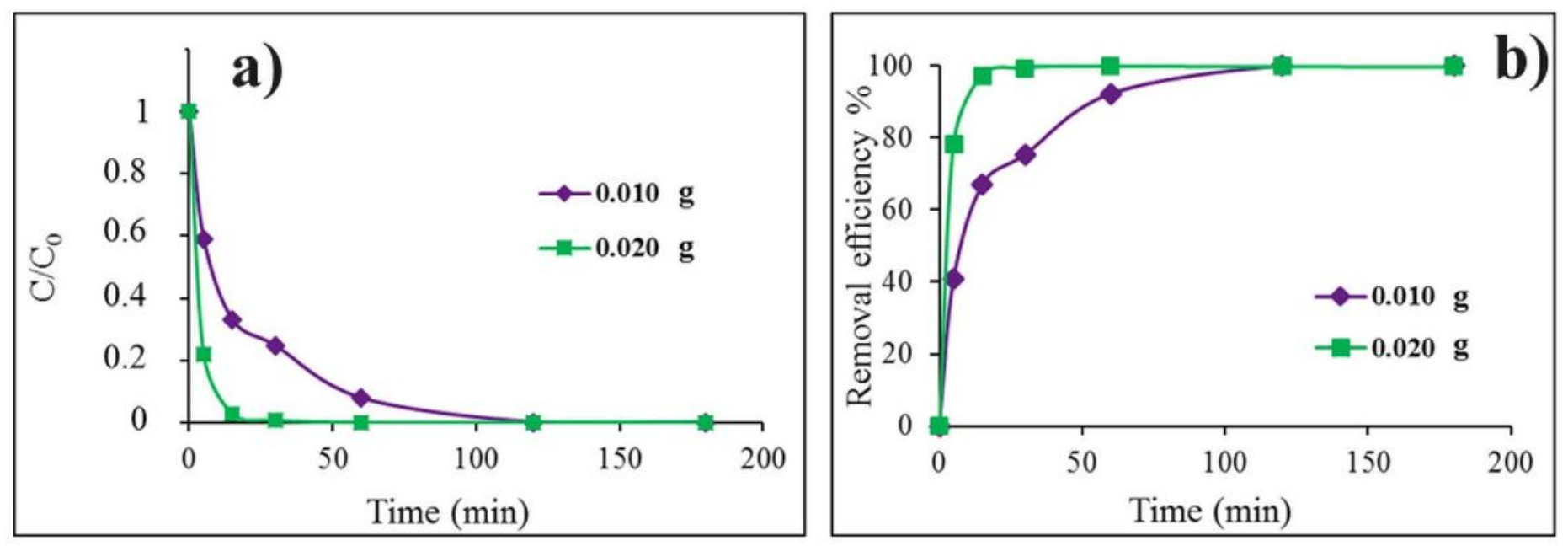

Figure 14

Effect of adsorbent dosage on the adsorption of AG-25 by Ch-rGO/Fe304. Experimental conditions: dye concentration $0.1 \mathrm{mg} \cdot \mathrm{mL}-1, \mathrm{RT}$, and $\mathrm{pH}=3$. 


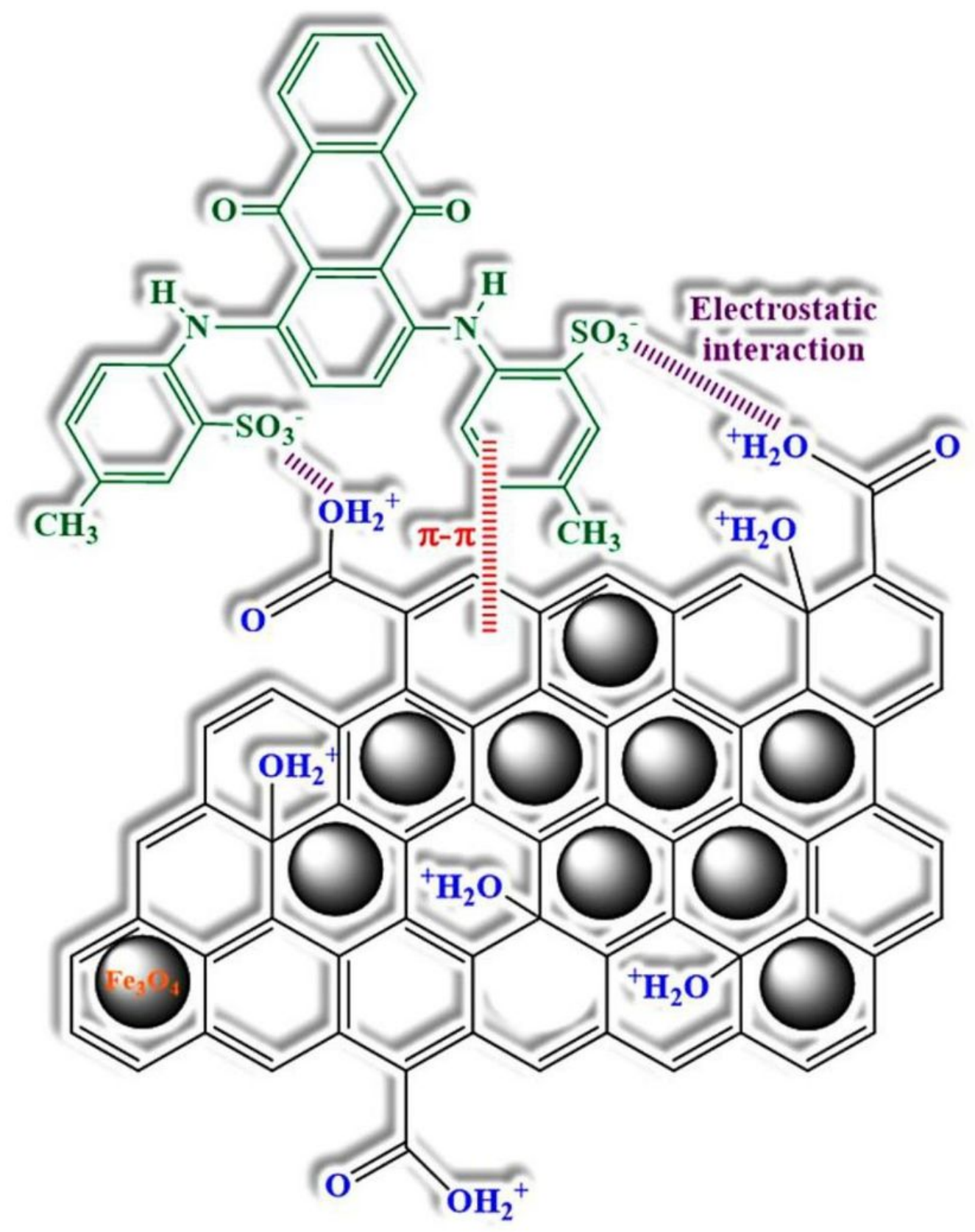

Figure 15

Adsorption mechanism of the AG-25 by $\mathrm{Ch}-\mathrm{rGO} / \mathrm{Fe} 304$ nanostructure. 

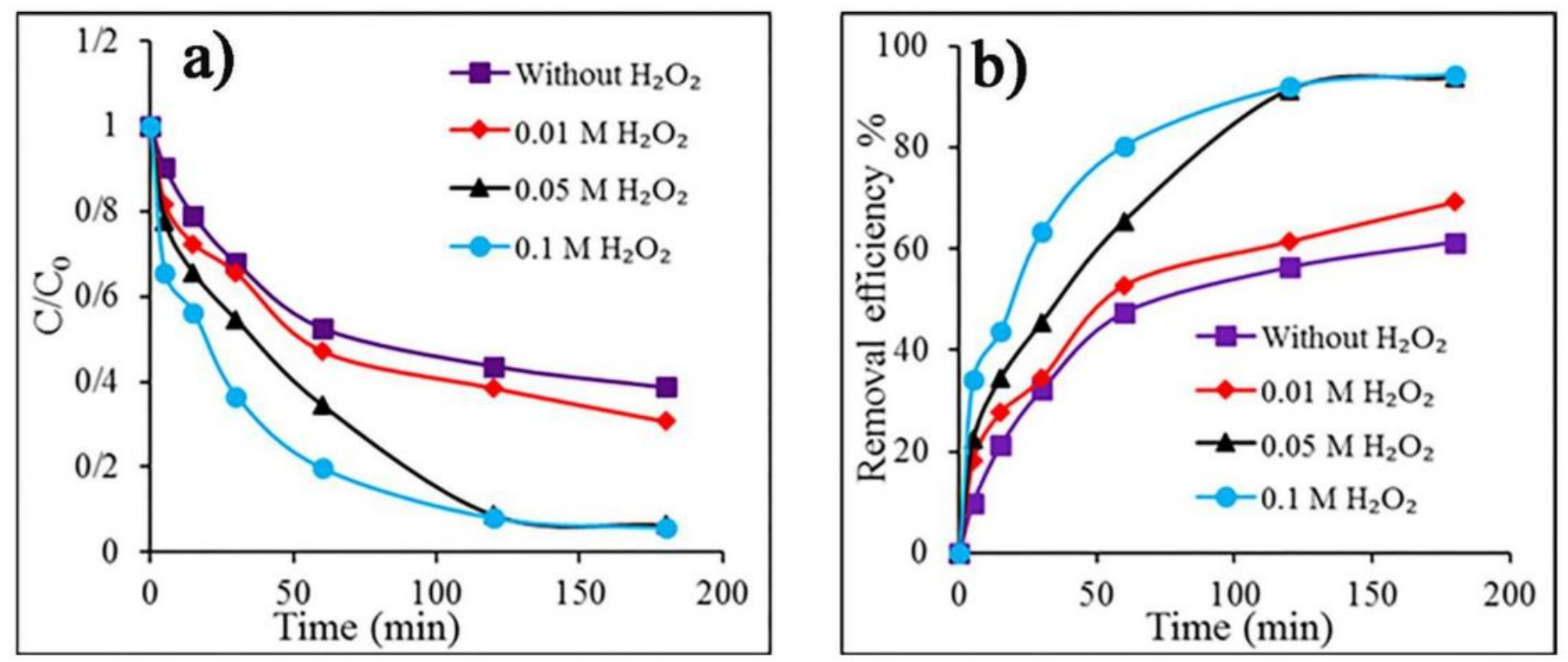

Figure 16

Effect of $\mathrm{H} 2 \mathrm{O} 2$ dosage on the adsorption of AG-25 by Ch-rGO/Fe304. Experimental conditions: dye concentration $0.5 \mathrm{mg} \cdot \mathrm{mL}-1, \mathrm{RT}$, adsorbent dosage $0.010 \mathrm{~g}$, and $\mathrm{pH}=3$. 


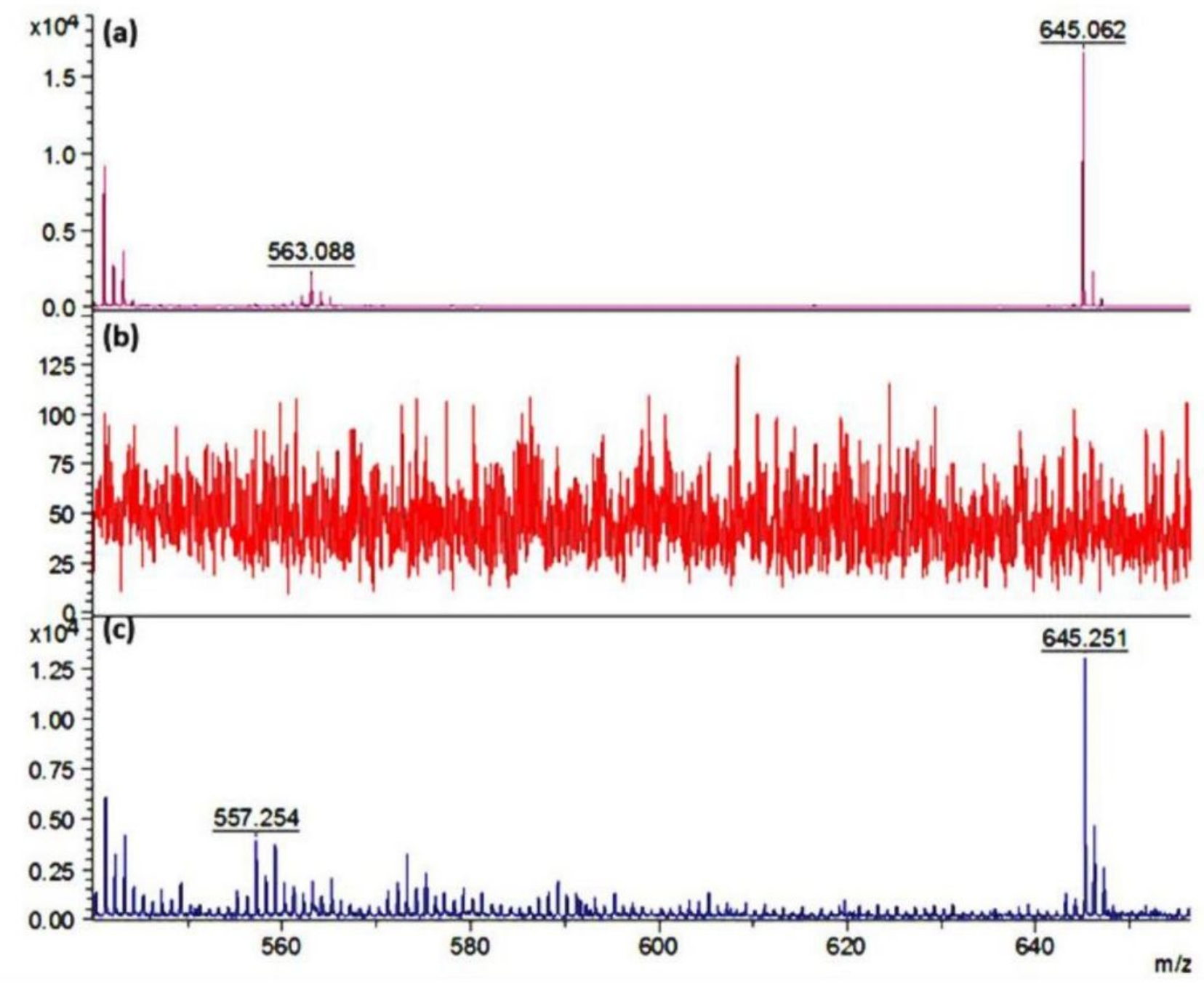

Figure 17

Comparison of average mass spectra of: (a) AG-25 (b) aqueous AG-25 solution after $3 \mathrm{~h}$ of Fenton's reaction over Ch-rGO/Fe3O4 in presence of $0.1 \mathrm{M} \mathrm{H} 2 \mathrm{O} 2$ (c) AG-25 after 3h with $\mathrm{H} 2 \mathrm{O} 2$ (0.1 M) and 3D-rGO $(0.010 \mathrm{~g})$. 


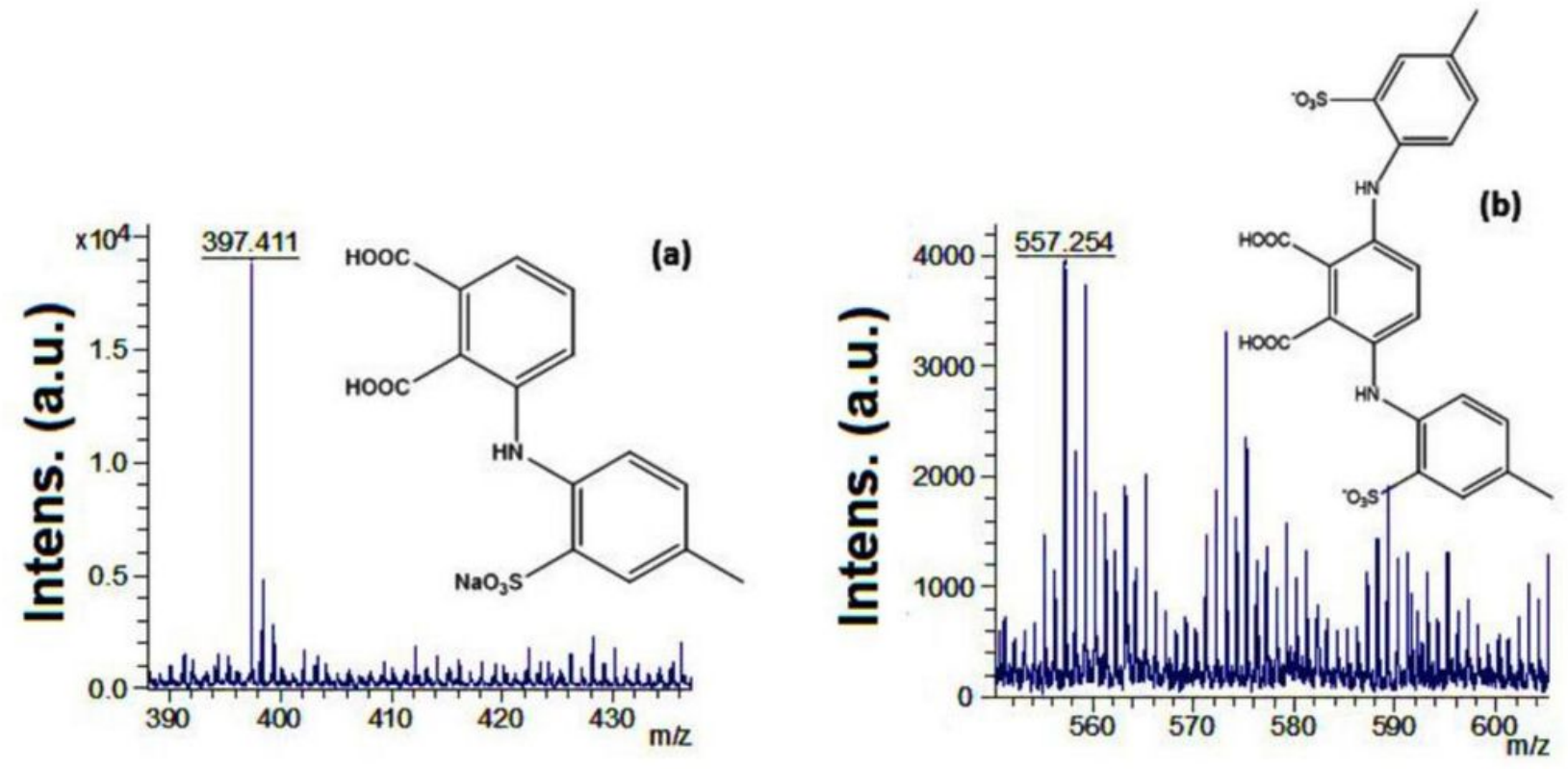

Figure 18

Mass spectra and the assignement of peaks observed in aqueous solution after dicoloration/degradation of $\mathrm{AG}-25$ by $\mathrm{H} 2 \mathrm{O} 2$ in presence of 3D-rGO.


Figure 19

Zoomed areas of the MALDI-TOF-MS spectra of aqueous solution after $3 \mathrm{~h}$ discoloration/degradation of AG-25 dye solution at $\mathrm{pH}=3$, over Ch-rGO/Fe3O4 nanocatalysts $(0.010 \mathrm{~g})$ and $\mathrm{H} 2 \mathrm{O} 2(0.1 \mathrm{M})$. 


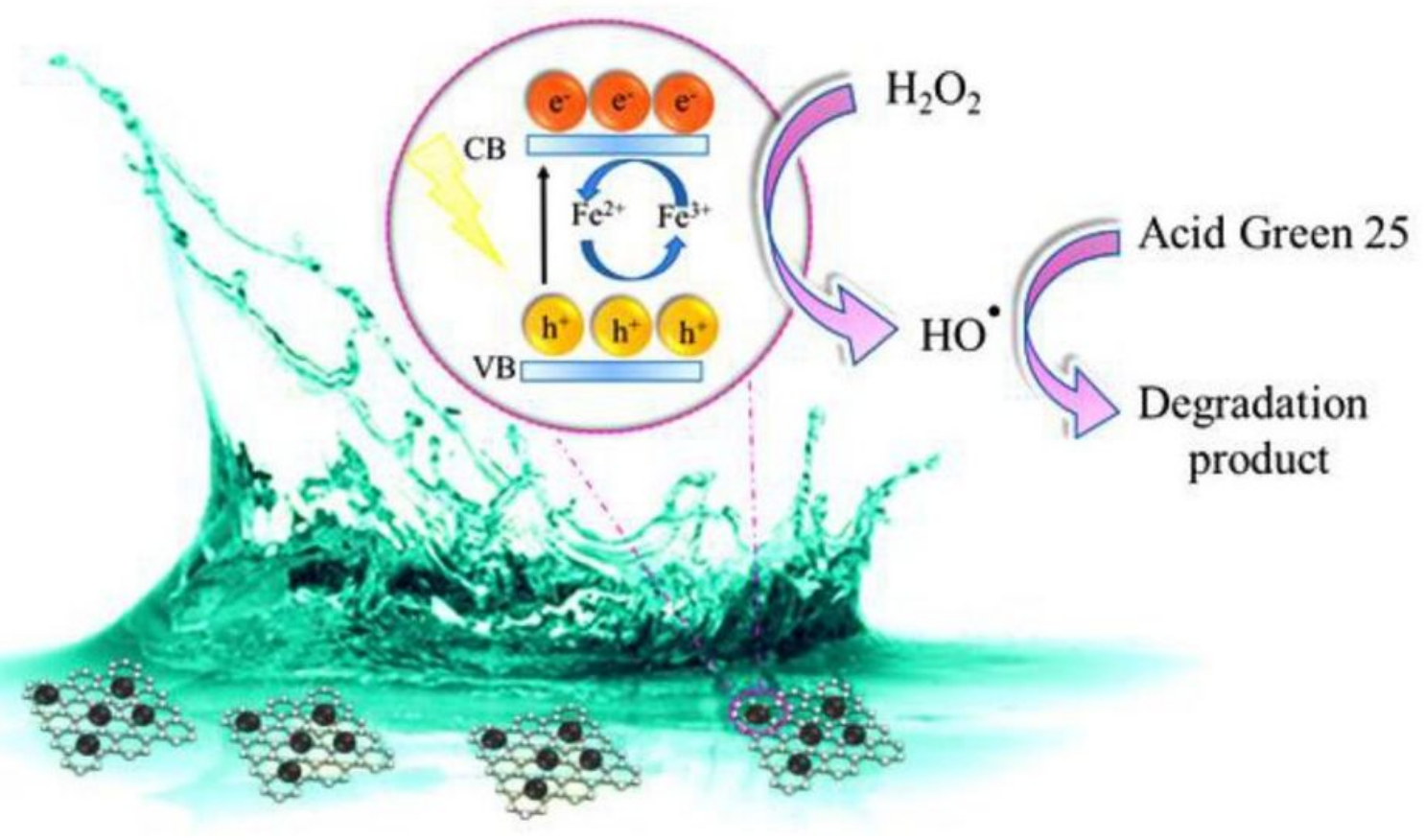

Figure 20

Proposed mechanism of AG-25 degradation in the 3D rGO/Fe304/H2O2 system. 